\title{
Leukemia Medical Application with Security Features
}

\author{
Radhi Rafiee Afandi ${ }^{1}$, Waidah Ismail ${ }^{1 *}$, Azlan Husin ${ }^{2}$, Rosline Hassan ${ }^{3}$ \\ 1 Faculty Science and Technology, Universiti Sains Islam Malaysia, Negeri Sembilan, Malaysia. \\ 2 Department of Internal Medicine, School of Medicine, Universiti Sains Malaysia, Kota Bahru, Malaysia. \\ ${ }^{3}$ Department of Hematology, School of Medicine, Universiti Sains Malaysia, Kota Bahru, Malaysia. \\ * Corresponding author. Tel.: +6 06 7988056; email: waidah@usim.edu.my. \\ Manuscript submitted January 27, 2015; accepted April 28, 2015 \\ doi: 10.17706/jsw.10.5.577-598
}

\begin{abstract}
Information on the Leukemia patients is very crucial by keep track medical history and to know the current status of the patient's. This paper explains on development of Hematology Information System (HIS) in Hospital Universiti Sains Malaysia (HUSM). HIS is the web application, which is the enhancement of the standalone application system that used previously. The previous system lack of the implementation of security framework and triple ' $\mathrm{A}$ ' elements which are authentication, authorization and accounting. Therefore, the objective of this project is to ensure the security features are implemented and the information safely kept in the server. We are using agile methodology to develop the HIS which the involvement from the user at the beginning until end of the project. The user involvement at the beginning user requirement until implemented. As stated above, HIS is web application that used JSP technology. It can only be access within the HUSM only by using the local Internet Protocol (IP). HIS ease medical doctor and nurse to manage the Leukemia patients. For the security purpose HIS provided password to login, three different user access levels and activity log that recorded from each user that entered the system
\end{abstract}

Key words: Hematology information system, security feature, agile methodology.

\section{Introduction}

In developing software the main objective is the user requirements with addition features which are triple "A" (Authentication, Authorization and Accounting) security features. Currently, many software in the market especially on the Hospital Information System. But some of the software did not meet the user requirement and lacking of the security features. For example Hematology Information System (HIS) has been developed by the medical doctor with the standalone application which required licenses for additional user. Therefore, this paper will the explain on the improvement and enhance that system in term of HIS with using local Internet Protocol (IP), design and implement the triple 'A' security elements.

We are using agile methodology that used in developing the HIS application which required the involvement of the user at the beginning until the end of the project. At the same time, we will perform normalization the database from the previous system. The HIS is to make an easy procedure for users in order to manage leukemia patients. The target users for this system are the admin, medical doctor and nurse.

In this paper explained the previous study in developing the software. In section 3, mentions on the Agile methodology that we used in developing the HIS. Next section explains data gathering and observation then explain on the design. Section 6 will explain on coding. Section 7 explains on the testing and section 8 on the 
result and analysis. Lastly we will conclude our finding in conclusion.

\section{Previous Study}

In the previous study include the two section which is previous study on software application and the second part will explain on the leukemia cells.

\subsection{Security Features in Developing a Software}

The application of various techniques of computerization in the medical field has helped medical doctors, researchers, specialists and patients in many ways such as blood medical images can be analysis [1]. Nowadays, there are many systems that related with Medical Information System (MIS) such as e-clinical system. There are a few existing software development such as Health, Safety and Environment System (HSES) on the web-based system and registration phase [2], Pet Shop Management System (PMS) [3] and Leukemia Information System (LIS) for collection, storage, retrieval and evaluation data [4]. All of the system does not fully concentrate on the security measure. It has been determined that in order to obtain a high level of security quality in Web-based applications system it is necessary to include good security practices during the whole software life cycle, and to make use of the available security assessment and security monitoring tools that provides to administrators, testers, and developers of valuable information for producing secure applications.

One of the important items in implementing the applications is system security and security frame. In the secure system is to understand that software is $100 \%$ secured [5)]. The main idea behind Software Security is to integrate the more level of security possible in software in order to diminish the possibilities of an attack [5]. A lot of software developments do not provide proper security because they were created with wrong suppositions in mind [5] such as that all users are friendly and will not be perform an attack, that requiring a password to login will prevent unwanted users to try to hack the application, and that a firewall is enough to protect a software from threats. Several approaches are identified often used in software development, which do not provide a valid solution to security issues in the final version of the product [6]. A Security Frame is a tool used in the creation of threat models, when is needed to identify threats and vulnerabilities [7]. It consists in a set of categories of recurring security vulnerabilities in an organized way that avoids overload of information, and helps to systematically and effectively reveals security threats [8]. In additional also required Authentication, Authorization and Accounting. These are the three basic issues that are encountered frequently in many applications [9]. Objective and measurable of security is playing an important roles in developing the software. One area in which progress is more tangible is software security assessment which can help to improve decision making on enterprise software. The software security assessment called by Vulnerability Distribution Scoring which evaluates as software product based on the characteristics of the vulnerabilities. [10]. Not only the software security but also security policy management is consider as critical to meet organisation needs and reduce potential risks because almost every organisation depends on computer network and the internet for their daily operations. The author [11] has introduced a policy framework called Chameleos-x which is designed to enforce security policies consistently across security-aware system with network services - primarily operating systems, firewalls and intrusion detection systems.

F. Montecucco [12] concerns on the ethical/legal when developing of clinically applied technologies, the collection and analysis of data to improve the Cardiovascular diseases. But by developing the system medicine it gives the opportunity of improving different steps in medical practice, from diagnosis to healthcare management, including clinical research. In the clinical decision-support system (CDSSs) was developed by [13] is to store and manage the clinical data, tools to alert clinicians of problematic situation or decision making tools to assist clinicians by mapping with the electronic health records. Currently our 
application only store and retrieve the information for patients. The author [14] has created an analytics platform for specifying and detecting clinical phenotypes especially on derived variables in electronic health record (EHR) data for quality improvement investigations.

The main objective in developing the software is to provide a model of what is needed in a clear, consistent, precise and unambiguous statement of the problem that needs to be solved. If the environment is not well the understood the design will be misleading and did not fullfill the object. Understand the user requirement one of the important tasks. [15]. Although the user design has been determine but the design patterns in object-oriented program play a main roles in source code that can help maintainers understand the design of a program. Through the detection, the understandability, maintainability and reusability of object-oriented programs can be improved. [16]. We developed our application using object-oriented program using Java Script Program (JSP). In developing the application, database playing an important role in allowing the implementation of searching methods on the data to reveal relationships. The data store and retrieve by using Structured Query Language (SQL) command in accessing the data [17]. After developing the application, we need to perform the testing. The test case prioritization techniques attempt to reorder the test cases manner that increases the rate at which faults are detected during regression testing. The prioritise test cases based on the total number of code. The testing not limited into the user testing but also code testing. [18], [19]. We also perform the integration testing between the program. After testing and the new software need to be release with the growing competition in the software industry. The software release process which broadly includes all the process that starts after the completion of development till the final deployment. The plan of the deployment need on time and changes also need to monitor. [20]

Nowadays, people are not looking for a traditional software development which is waterfall methodology. [21] mention recent studies show that traditional teaching strategies such as presentation of theory and lectures are differences scenario when working in industry. They have developed a training method called Software Kaizen for high-performance environment. From the study, shows good results in learning, posture change and teamwork and some of the expected characteristics of high-performance teams. Agile software engineering and user-centered design are two important development processes for ensuring that an application has good user experience. [22]. From the study by [23] communities of practice (CoPs) are groups of experts who share a common interest or topic and collectively want to deepen their knowledge. The use of CoPs for knowledge sharing and coordination in large-scale agile software developmends. From their study of large software development organization that successfully used CoPs to suppor their large-scale agile implementation as their transformation from the waterfall model to lean and agile.

In this paper highlighted the Hematology Information System. Authentication based on the role-based where doctor and nurse have differences role in the system. Authorization is the user name and password before access into the system. Accounting is the collection of the activity from access into the system until logout. From the literature review, mention that agile methodology has improved the high-performance development and it has been used in the large-scale software development. We performed our study in using agile methodology.

\subsection{Leukemia Cells}

Cancer has become a data-intensive area of research, with increasing rate of developments in data collection technologies and methodologies. In 1895, Wilhelm Roentgen discovered that X-ray tubes, used extensively for imaging bones and then for treating a variety of conditions. The technicians who ran the Radiograph machines, as well as many of the exposed patients, contracted skin tumours and leukaemia [24]. Accurate diagnosis and classification of blast cells is an extremely valuable requirement for the precise diagnosis of leukemia and has a positive impact on treatment and prognosis [25]. 


\subsubsection{Types of leukemia}

Leukemia is a disease of unknown cause where the bone marrow produces large numbers of abnormal cells white blood cells that stop developing before maturity [26]. There are four main types of leukaemia, namely Acute Lymphoblastic Leukemia (ALL), Acute Myeloid Leukaemia (AML), which is used as a case study in the thesis, Chronic Lymphocytic Leukemia (CLL) and Chronic Myeloid Leukaemia (CML). Most commonly, acute leukaemia patients are referred to specialist units for evaluation. Treatment is based on chemotherapy through the veins, lasting four to six months, which also kills normal body cells. Leukaemia can be diagnosed by blood tests while a bone marrow test serves to decide on the best choice of treatment.

\subsubsection{Flow chart of patients admitted with leukemia}

Fig 1 shows the steps that need to be taken by a hematologist in order to diagnose a patient with acute leukemia. Table 1 provides a more detailed explanation of the individual steps in Fig. 1 [27].

Table 1. Analytical Description of Each Step in Fig. 1

\begin{tabular}{|c|c|}
\hline Steps & Descriptions from Figure 1 \\
\hline 1 & Patient warded in hospital. \\
\hline 2 & $\begin{array}{l}\text { In acute leukaemia patients, the White Blood Cell (WBC) count and morphology will be } \\
\text { abnormal. } \\
\text { Doctor will suspect that a patient has leukaemia based on: } \\
\text { a) Clinical presentation: patient presented with hepatosplenomegaly and/or } \\
\text { lymphadenopathy. } \\
\text { b) Abnormal blood count: haemoglobin and platelet count is low, WBC is normal, } \\
\text { low or high. } \\
\text { Blood test will be taken from the patient. } \\
\text { In a healthy adult the differential WBC test should show the following results: } \\
\text { - Neutrophil - } 40 \%-70 \% \\
\text { - Eosinophil - } 5 \% \\
\text { - Basophil - } 1 \% \\
\text { - Monocyte - } 6 \%-10 \% \\
\text { The blood count will be performed by the Machine. } \\
\text { In case of clinicaly suspicious and abnormal blood count specimensa a blood smear is } \\
\text { prepared and the slide is referred to a haematologist for examination. }\end{array}$ \\
\hline 3 & $\begin{array}{l}\text { The blood smear is scanned through a microscope by a haematologist to see the white } \\
\text { blood cell morphological }\end{array}$ \\
\hline 4 & $\begin{array}{l}\text { If the blood smear test reveals no evidence of leukaemia, i.e. } \\
\text { normal blood cell count and morphology, other underlying causes need to be } \\
\text { investigated. }\end{array}$ \\
\hline 5 & $\begin{array}{l}\text { If the patient is suspected of suffering from leukaemia, bone marrow sample is required } \\
\text { to confirm the diagnosis. }\end{array}$ \\
\hline 6 & $\begin{array}{l}\text { The marrow smear is scanned under a microscope by a haematologist with } 10 \mathrm{x}, 40 \mathrm{x} \text { and } \\
\text { 100x magnifying power. }\end{array}$ \\
\hline 7 & $\begin{array}{l}\text { The haematologist will calculate the WBC differential count manually preferably based } \\
\text { on } 300-500 \text { cells }\end{array}$ \\
\hline 8 & $\begin{array}{l}\text { Blasts should account for about } 20 \% \text { of cells, based on the WHO classification. Less than } \\
5 \% \text { is considered normal. }\end{array}$ \\
\hline 9 & The image allows identification of ALL or AML. \\
\hline 10 & If the patient diagnosed with ALL then required treatment. \\
\hline 11 & $\begin{array}{l}\text { In the case of AML, the subtype must be identified as either M3 or non-M3 (M0-M7 } \\
\text { except M3). }\end{array}$ \\
\hline 12 & $\begin{array}{l}\text { If the patient is suspected as M3 based on the blood smear and bone marrow smear test, } \\
\text { Cytogenetic/molecular follows to confirm the diagnosis. }\end{array}$ \\
\hline 13 & Confirm M3: Treatment for M3; All-Trans-Retinoic-Acid (ATRA). \\
\hline 14 & If non-M3 - Another Chemotherapy \\
\hline
\end{tabular}

\section{Methodology}

The objective of the paper is to develop software application HIS in HUSM by collecting the user requirements. We choose Agile methodology in developing the HIS where from the previous study mention 
agile methodology has proven better than traditional study and last objective is to develop the security framework by using triple " $\mathrm{A}$ " elements (authentication, authorization and accounting) . Below in the Figure 1 show the Agile Methodology that we used in developing the HIS. In this methodology, we used requirement and analysis, design (user interface design, database design and system design), coding and testing were perform repeatedly until user satisfied before we implemented.

The activities carried out in HIS in Table 3 which illustrates the Fig. 2.

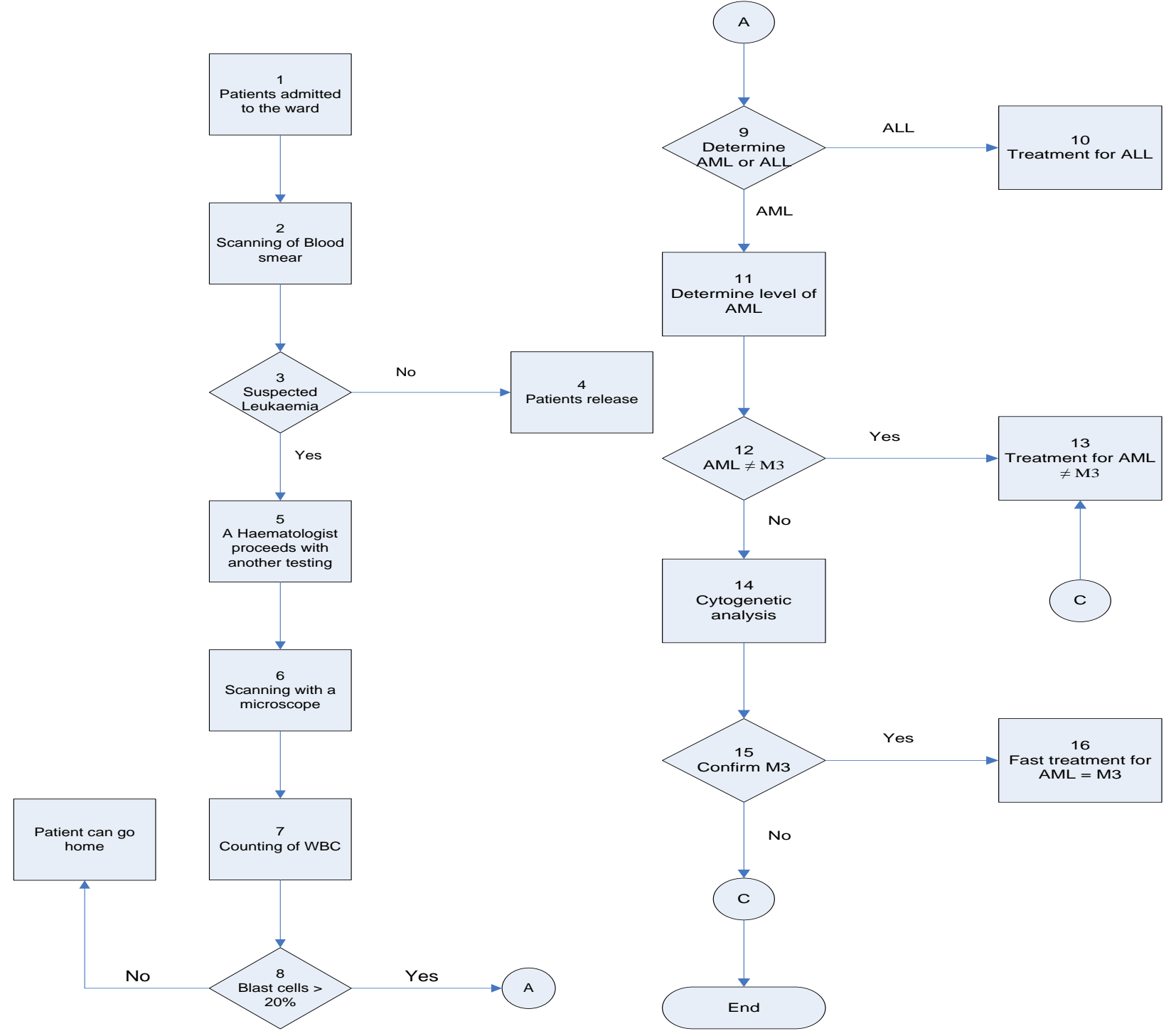

Fig. 1. Steps to confirm AML - M3.

\section{Data Gathering and Observation}

The development of HIS in Hospital Universiti Sains Malaysia (HUSM). Medical Doctor at Department of Hematology was interviewed to understand the user requirement and the user interface design. In order to achieve the first objectives, an interview was conducted with medical and the system user at Hematology Department. The questionnaires are based on the qualitative method. The questions can be referred in Appendix A. Based on that, we understand the current process and the problem in the current system of Hematology.

\section{User Design, System Design and Database Design}

In the current situation for HIS, the software application has been developed but there is limitation where 
the application needs licenses if required more users, lacking on the security features and database is not been normalized. Fig. 3 and Fig. 4 are the interface of existing system that used at Hematology Department HUSM.

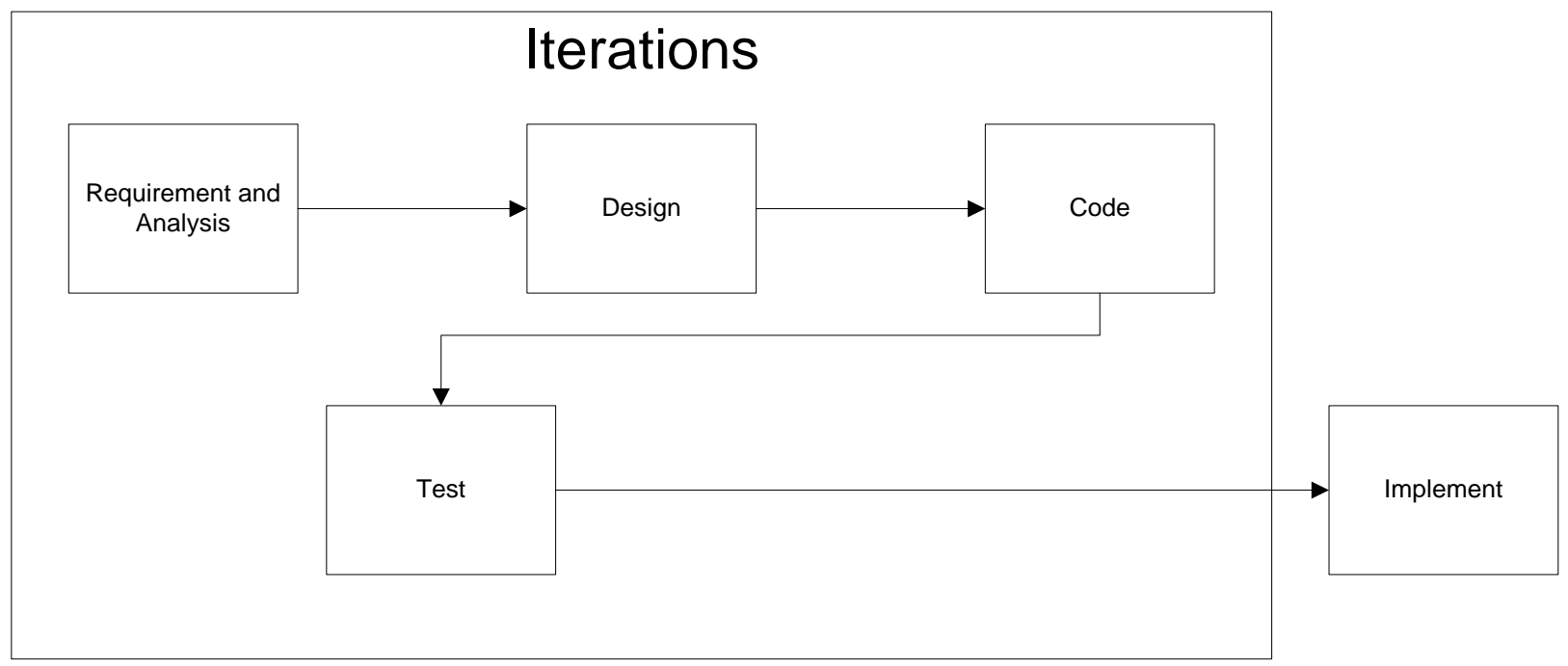

Fig. 2. Agile methodology.

Table 2. Process in Developing HIS

\begin{tabular}{|c|c|}
\hline Phases & Descriptions \\
\hline Requirement and analysis & $\begin{array}{l}\text { Goals: } \\
\text { To identify the project problem statements, research questions, objectives and motivations } \\
\text { Tasks: } \\
\text { Define the project problem statements, research questions, objectives, motivations and scope. } \\
\text { Outputs: } \\
\text { The project problem statements, objectives and scope }\end{array}$ \\
\hline Design & $\begin{array}{l}\text { Goals: } \\
\text { The design phase consists of logical and physical design. The goals in this phase are to design } \\
\text { and model the system design using UML diagram and produce a detail design and model for } \\
\text { the system. Design the prototype model and the system interface using graphic software tools. } \\
\text { Tasks: } \\
\text { Build and design the system structure. Determine the system flow. } \\
\text { Transfer the system requirements into system design and system model. Draw use case } \\
\text { diagram and sequence diagram. Design and build the interface of the system. } \\
\text { Output: } \\
\text { The use case, sequence diagram and user interface built }\end{array}$ \\
\hline Coding & $\begin{array}{l}\text { Goals: } \\
\text { Coding the component and modules for the system using JSP technology and MySQL for } \\
\text { database. } \\
\text { Tasks: } \\
\text { Transfer the design and model of the system into coding part. } \\
\text { Outputs: } \\
\text { Full coding of the system will be constructed after the design process. Therefore, complete } \\
\text { system will be produced within the complete functionality. }\end{array}$ \\
\hline Test & $\begin{array}{l}\text { Goals: } \\
\text { To test part of the system. } \\
\text { Tasks: } \\
\text { Provide input and unexpected data value for testing during implementation. Repair any errors } \\
\text { of bugs during the implementation. } \\
\text { Outputs: } \\
\text { The system will be tested whether it is working or not after the developing of the system. }\end{array}$ \\
\hline Implement & $\begin{array}{l}\text { Goals: } \\
\text { To test full version system with real time environment. } \\
\text { Tasks: } \\
\text { Run the Hematology Information System on the different environment, such as different } \\
\text { computer and Operating System (OS). Deploy the project based on user requirement and } \\
\text { linkage with other department. } \\
\text { Goals: } \\
\text { A system that is capable to operate correctly. }\end{array}$ \\
\hline
\end{tabular}




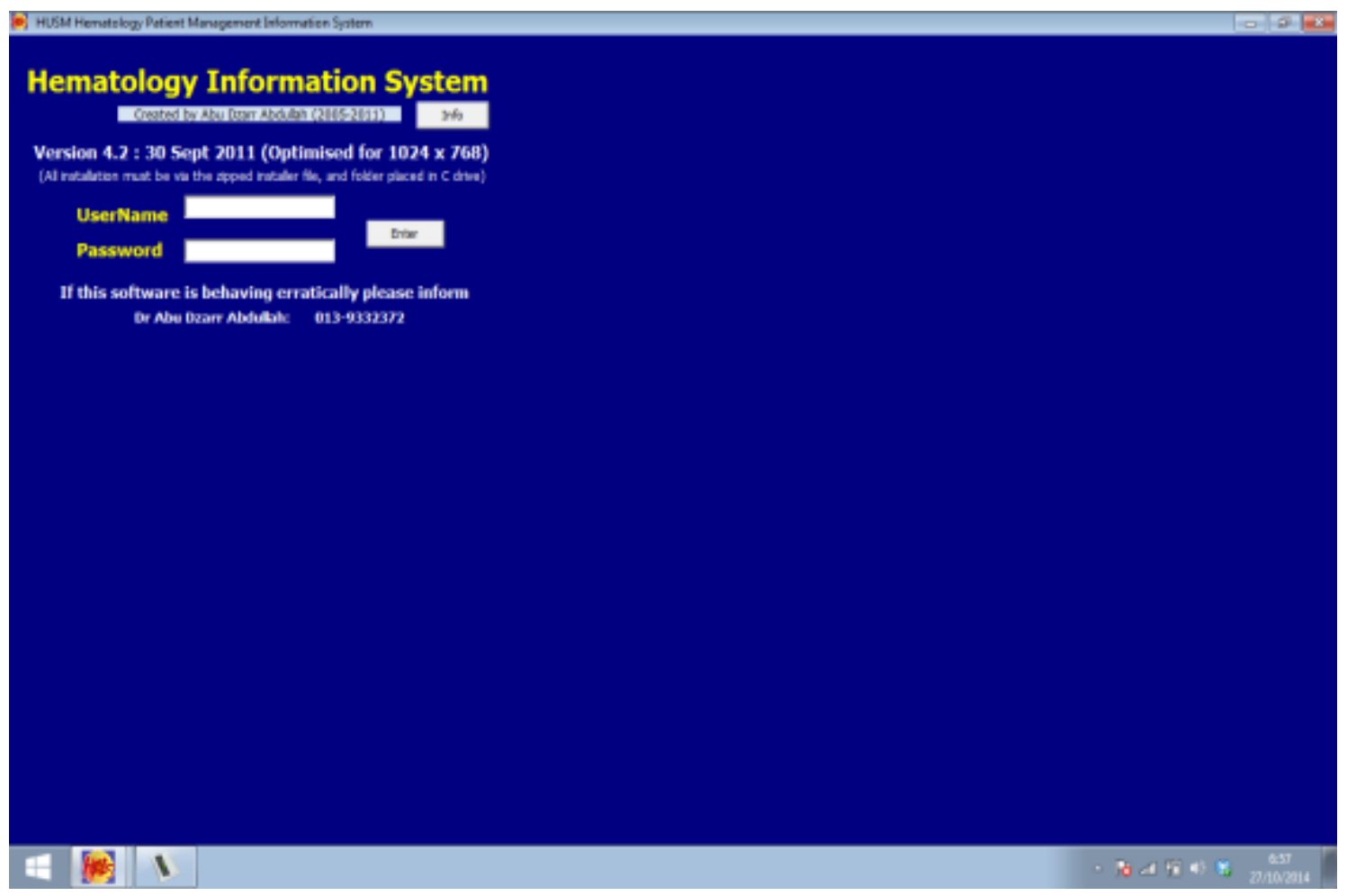

Fig. 3. Login page.

Fig. 3 shows the login page for the existing system at Hematology Department and Then Fig. 4 shows the patient's profile page from the existing system. The design look nice, but some of the field provided are not fully functional.

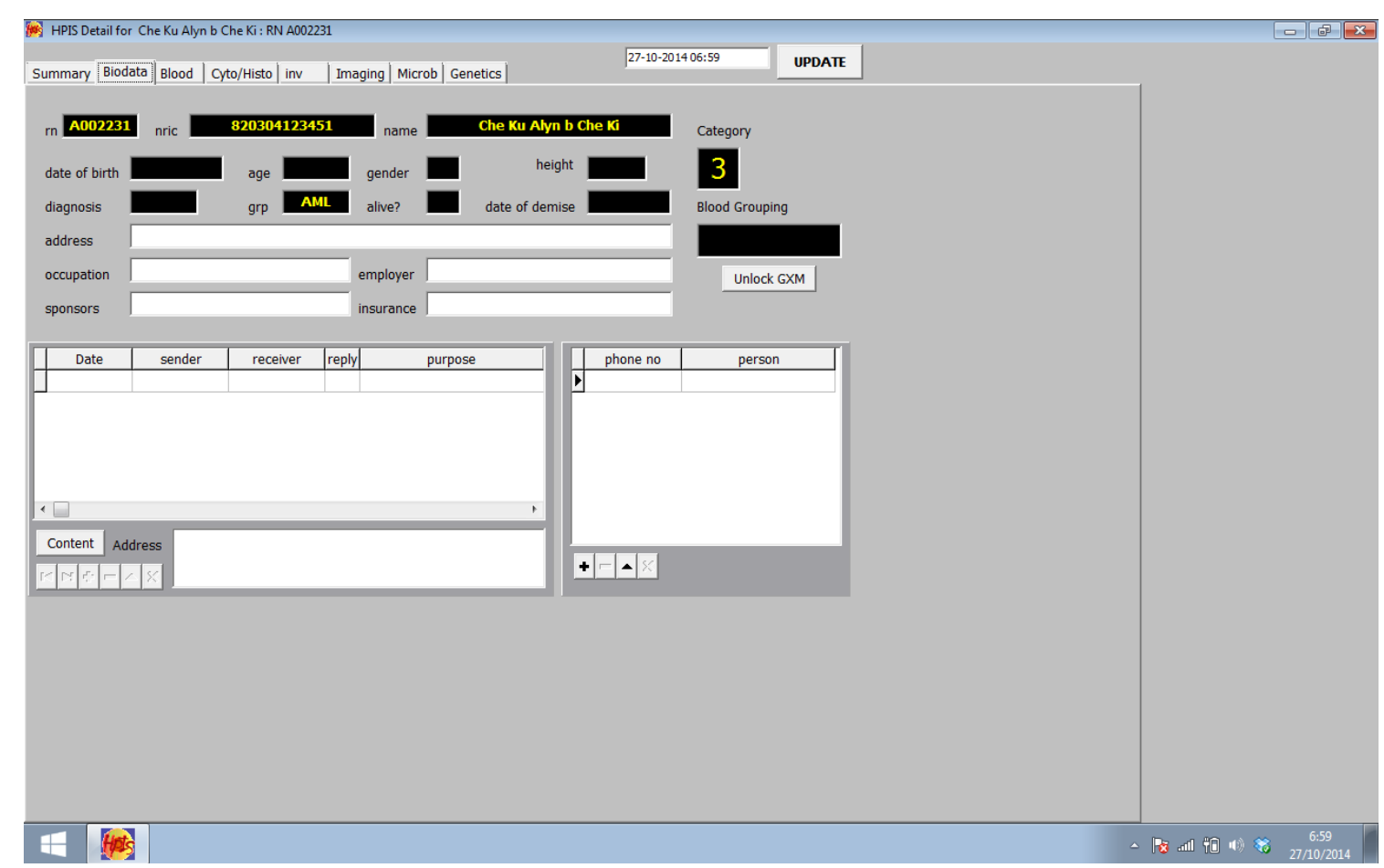

Fig. 4. Patient's profile.

\subsection{User Design}

We performed the agile methodology which needs user involvement from beginning. The first user design 
as shown in the Fig. 5 and Fig. 6 where the users are not keen with the design. Then we change the design as show in the Fig. 7 and Fig. 8. In a conclusion we have completed the design with agree by medical doctor at Hematology Department. The design of each page shows the different function respectively. Further discussions in this section involve with system structure, system architecture and system design.

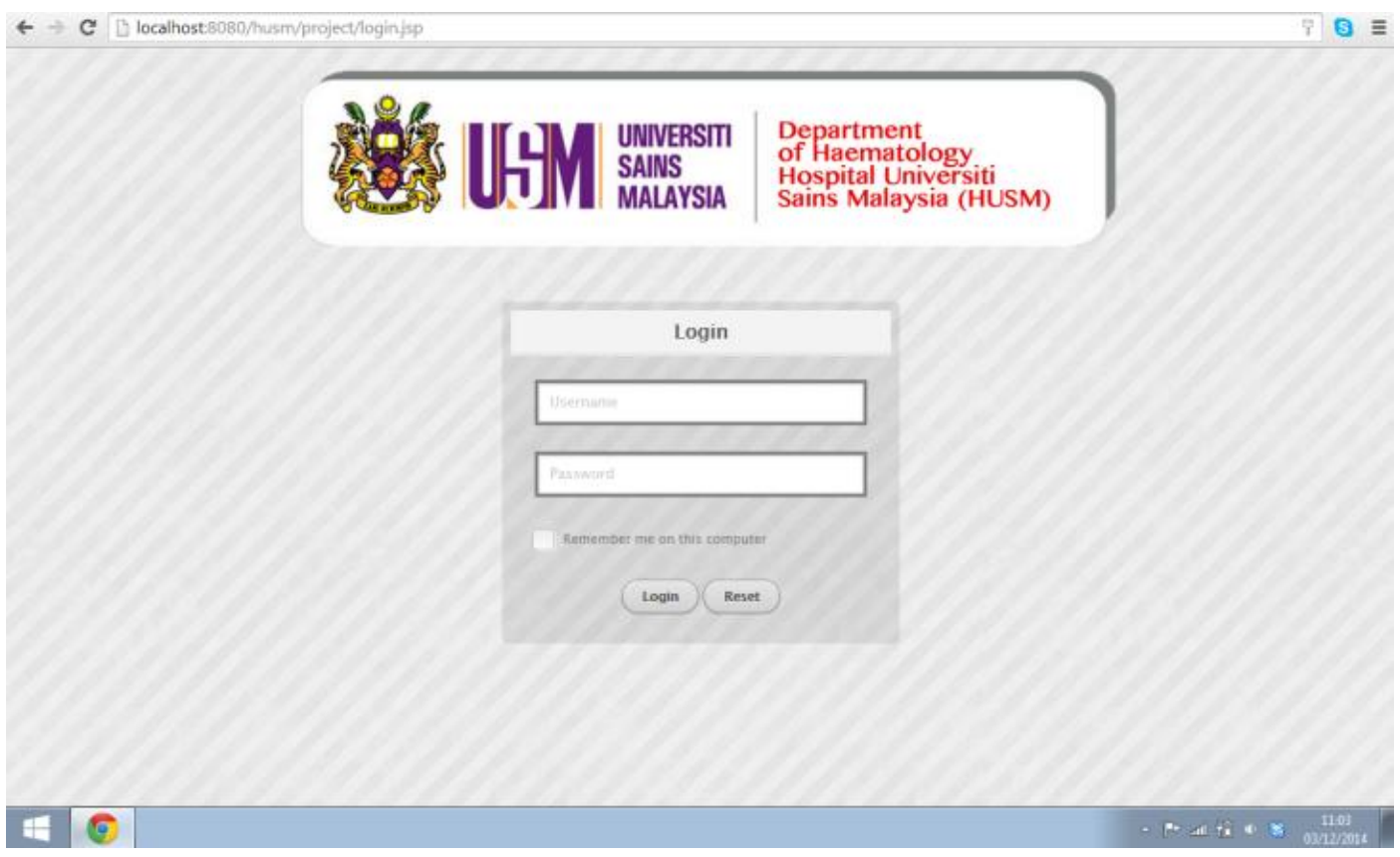

Fig. 5. Login page.

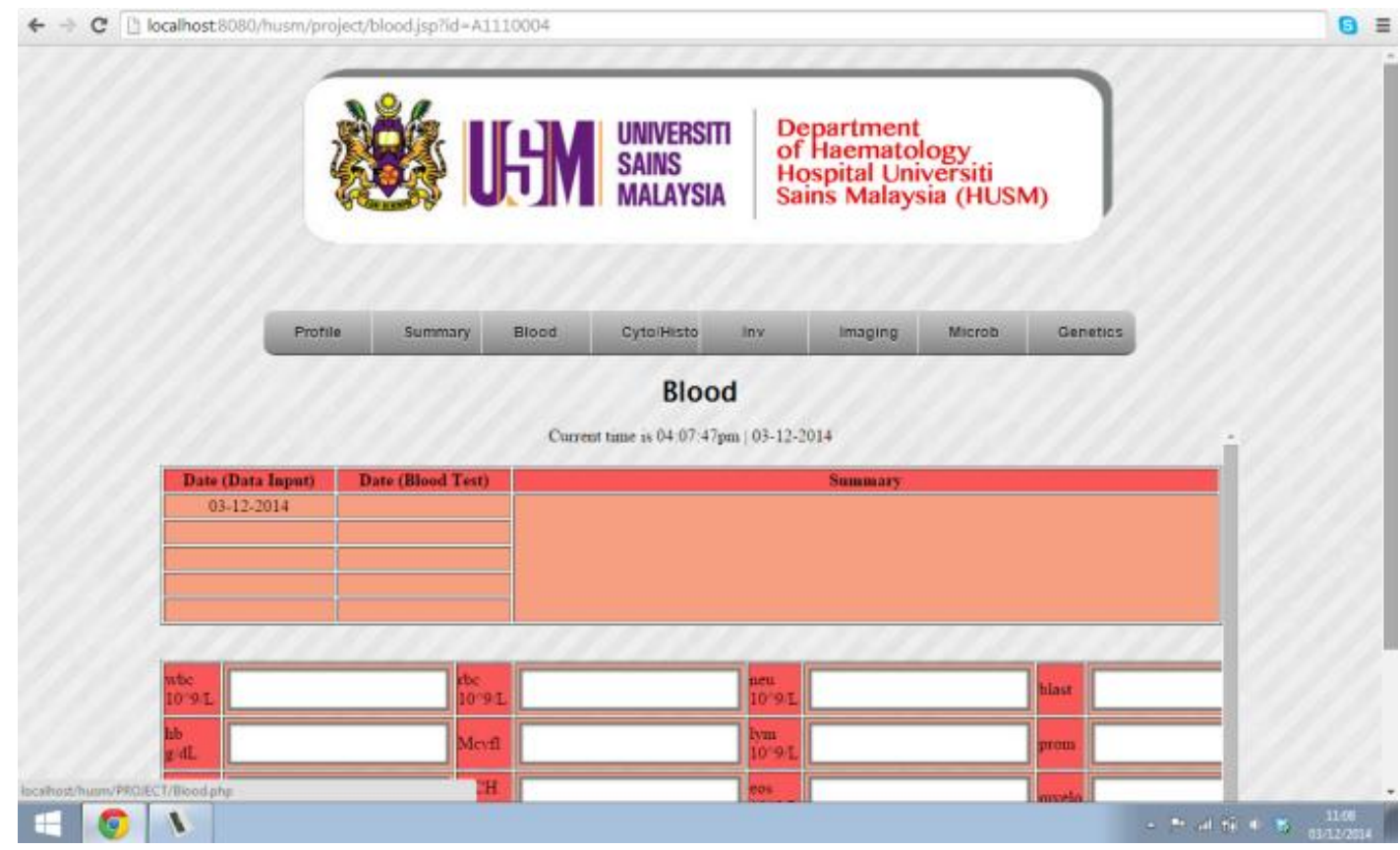

Fig. 6. Blood series.

HIS is capable to offer 12 pages that perform difference task and function for difference interface respectively. The medical doctors were accepted these latest designs based on the user requirement. Fig 7 to offer different types of important function for the user. Fig 8 show the activity log in the menu. Other menu design can be found in the Appendix B where we have implemented the authorization each user has own roles of job for example nurse and doctor. 


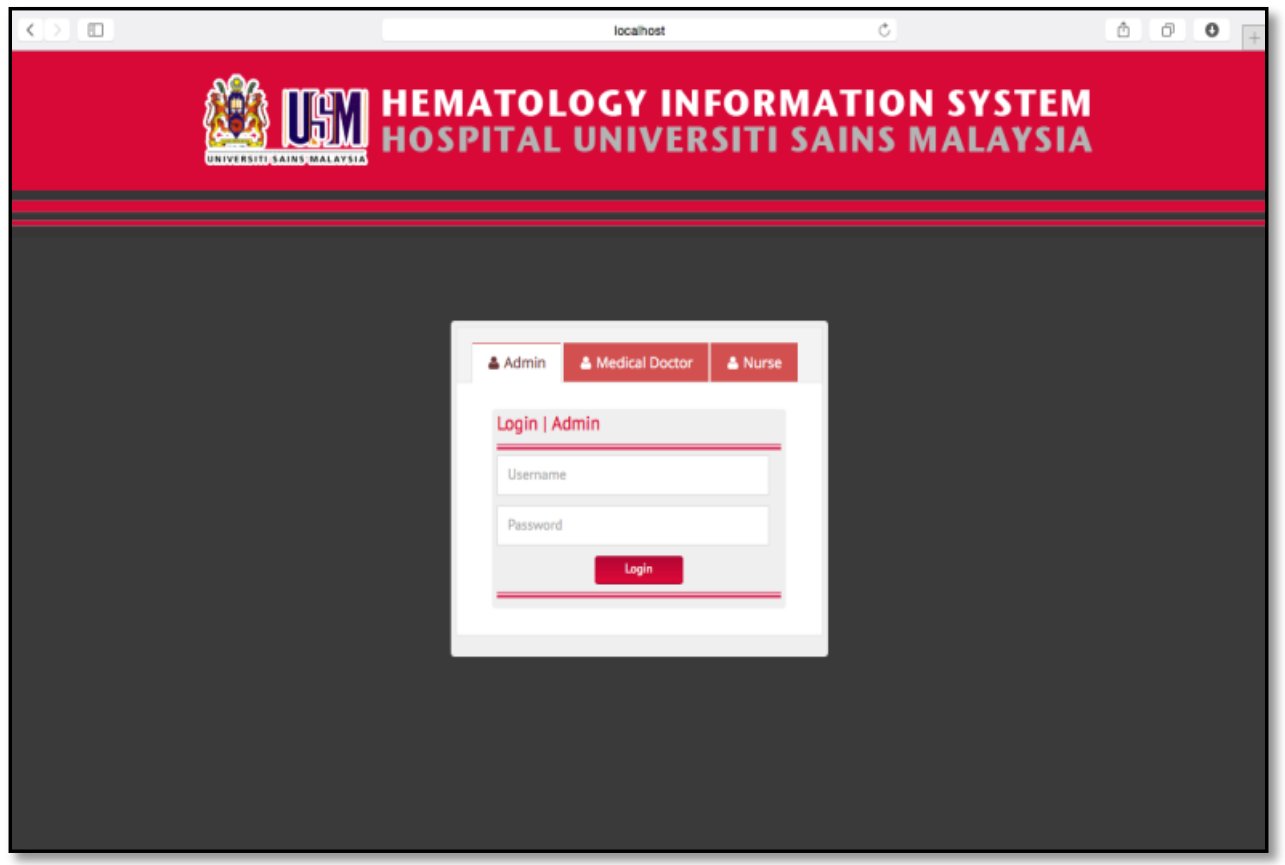

Fig. 7. HIS Login page.

\begin{tabular}{|l|l|}
\hline Part & Description \\
\hline User tab & There are 3 types of user, which each of user performed the different task \\
\hline Login field & User must enter their username and password in the provided field \\
\hline
\end{tabular}

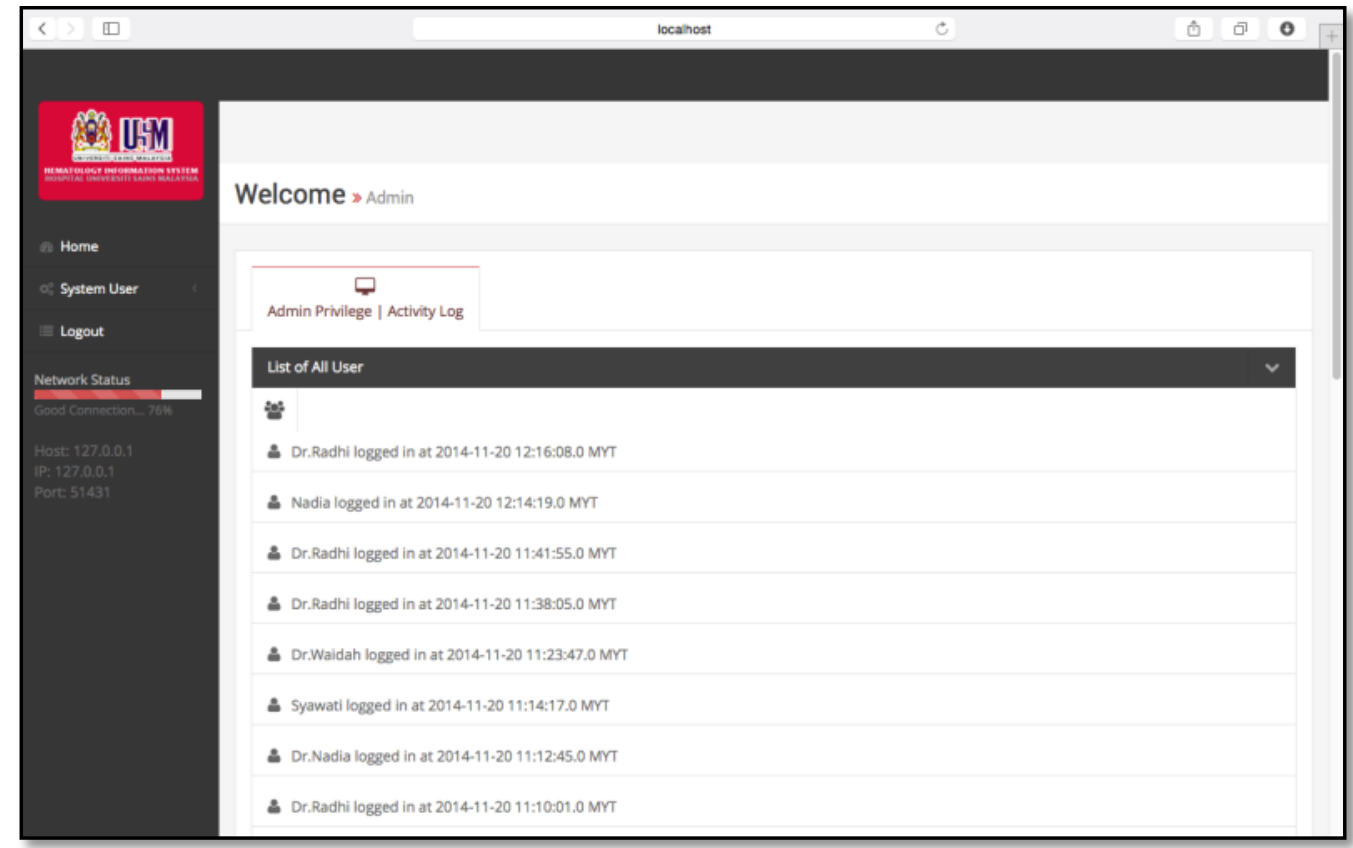

Fig. 8. Activity log.

\begin{tabular}{|l|l|}
\hline Part & Description \\
\hline Home (sidebar) & List of all system user appear on the screen once admin login into the system \\
\hline System user (sidebar) & Admin can register new medical doctor and nurse to use the system \\
\hline Logout (sidebar) & Clear the current session and logout to the system \\
\hline
\end{tabular}

\subsection{HIS Structure}


Medical doctor in hematology department manually updated the data. It is easier for the medical doctor to maintain and enhance the patient's data. Fig. 9 illustrates the structure of HIS that contains 3 phases; there are interface layer, abstract layer and physical storage layer. The user interface designs of the system are delivered on interface layer, while the process of the system and storage are occurs on abstract layer and physical storage layer respectively. To make the system running properly, the three layers of the system structure must have integration within it.

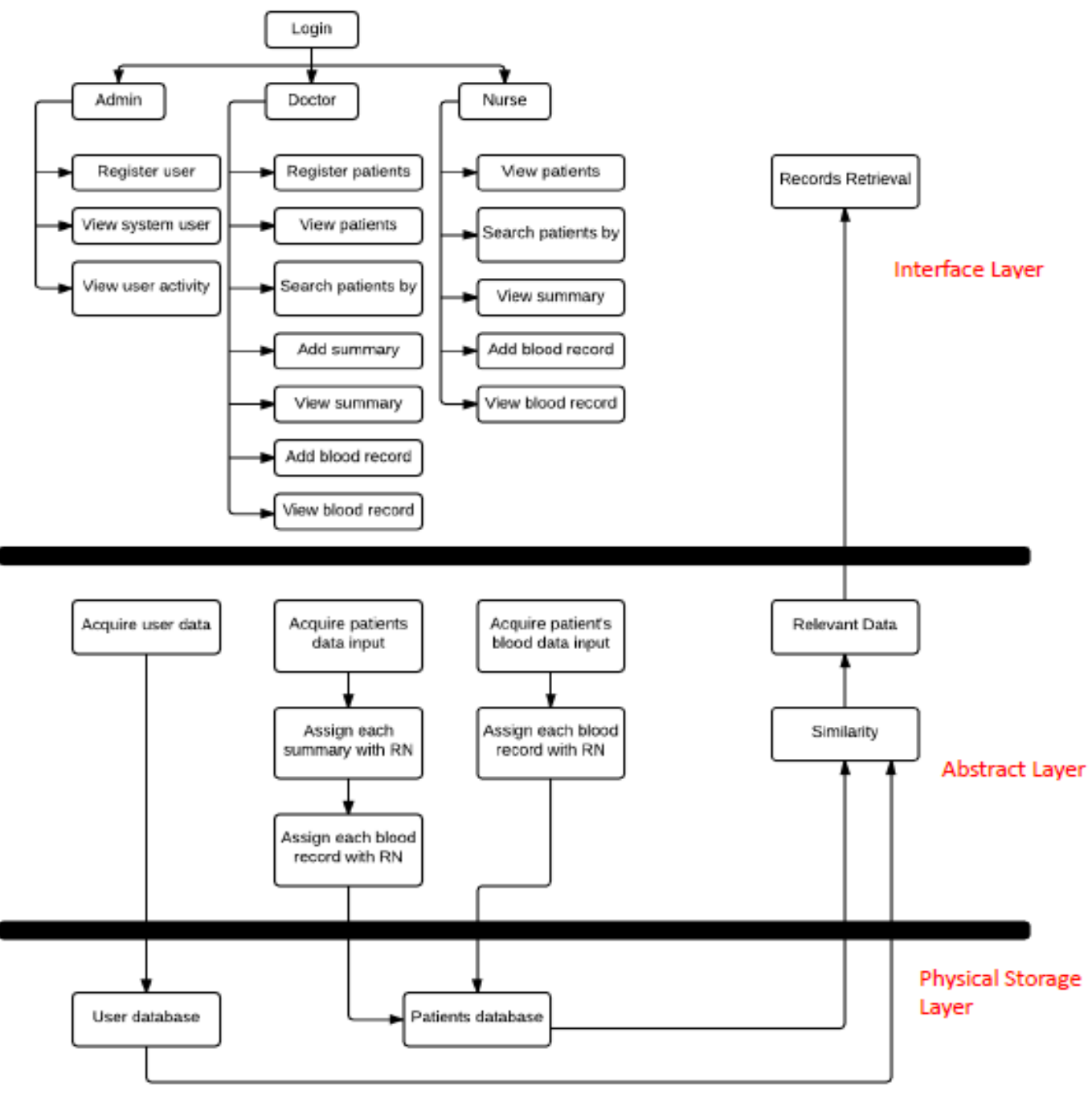

Fig. 9. HIS structure.

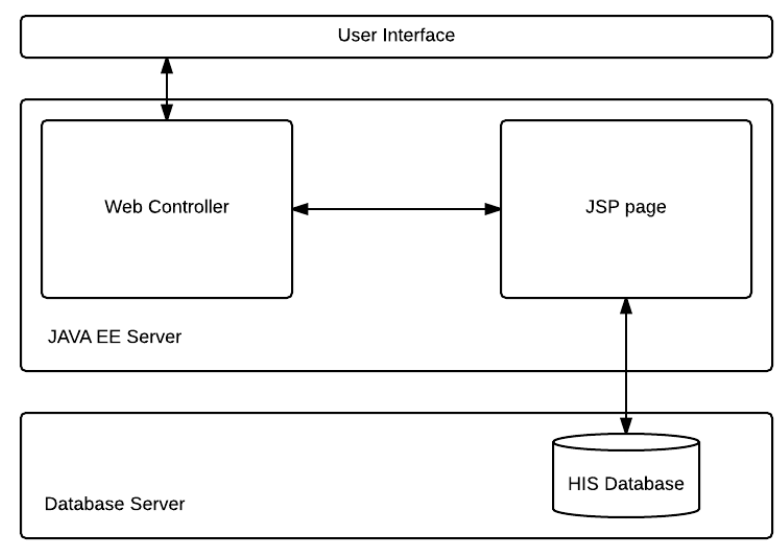

Fig. 10. Model of system architecture. 


\subsection{HIS System Architecture}

The system architecture of HIS consists of 3 parts as shown in Fig. 10. There are presentation layer (User Interface), business layer (Java EE Server) and data layer (Database Server). From the design, it consists of 1 database with 3 main modules, the admin module, medical doctor module and nurse module. The admin module is designed to manage the user of the system. The medical doctor and nurse module is designed to manage information relating to patient's personal and medical information. The HIS database is used to store user and patient's information, which includes the personal data, clinical summary and blood series record.

\subsection{HIS Database Design}

Database Design show in Fig. 11 is the relationship between the entity within the HIS. For example one patient can have multiple blood series and clinical summary. The result of blood series will be taken before chemotherapy and after chemotherapy. As for security reason, in the medical records, the data cannot be deleted or updated but only add the new one.

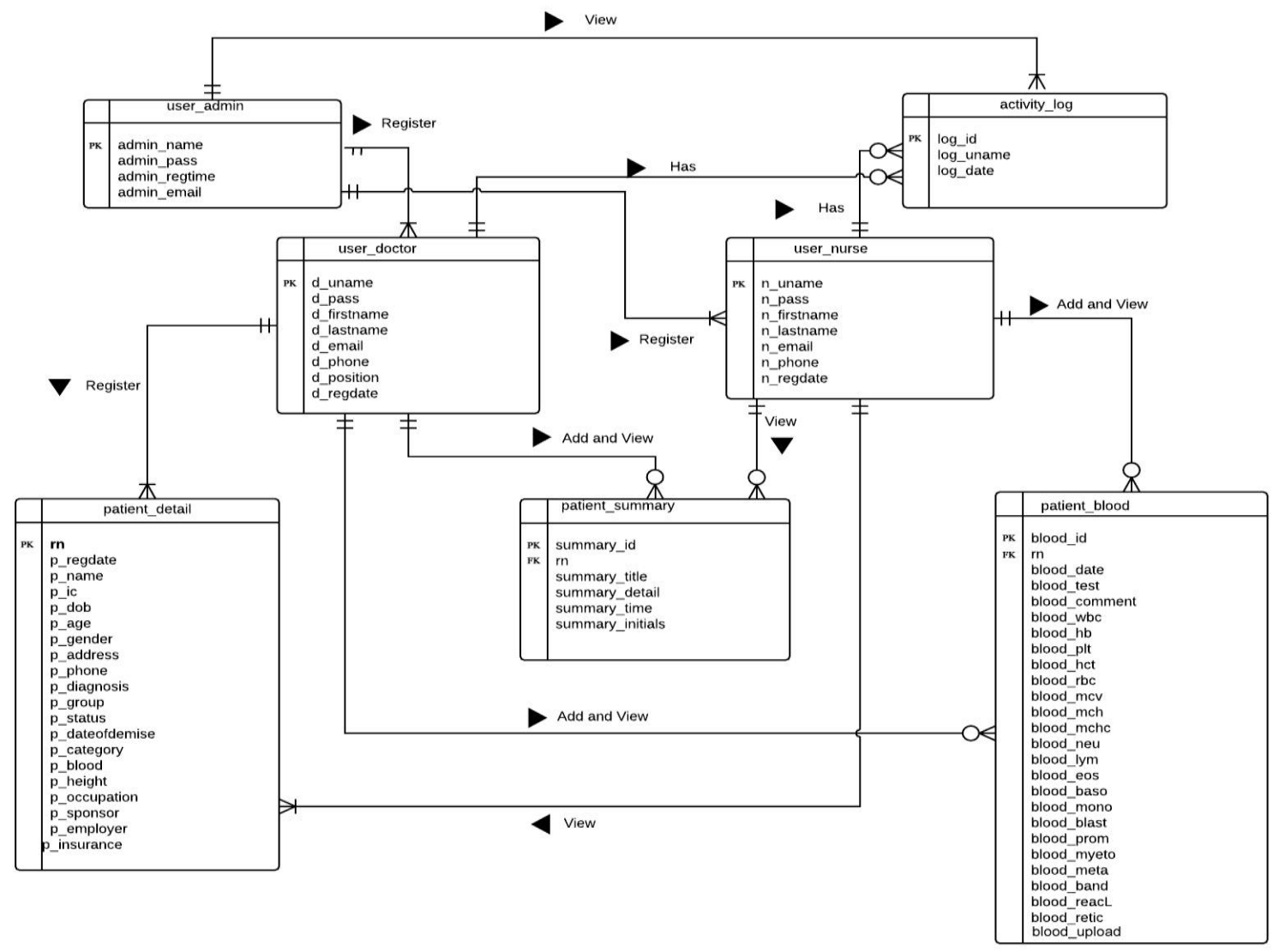

Fig. 11. Entity relationship diagram (database design).

\subsection{HIS Sequence Diagram}

Fig. 12 shows the model flow of logic within HIS in a visual manner. It enables to document and validate the system logic and is commonly used for analysis and design purposes.

\subsection{HIS Use Case Diagram}

Use case diagram describes the scenario of the system. This scenario is an interaction between actors and the use case. In Fig. 13, actors involved in this use case are admin, medical doctor and nurse while the use case involved are register new user, view user activity log, register new patients, update patient details, add 
clinical summary, view patient records, search patients and add patient's blood details.

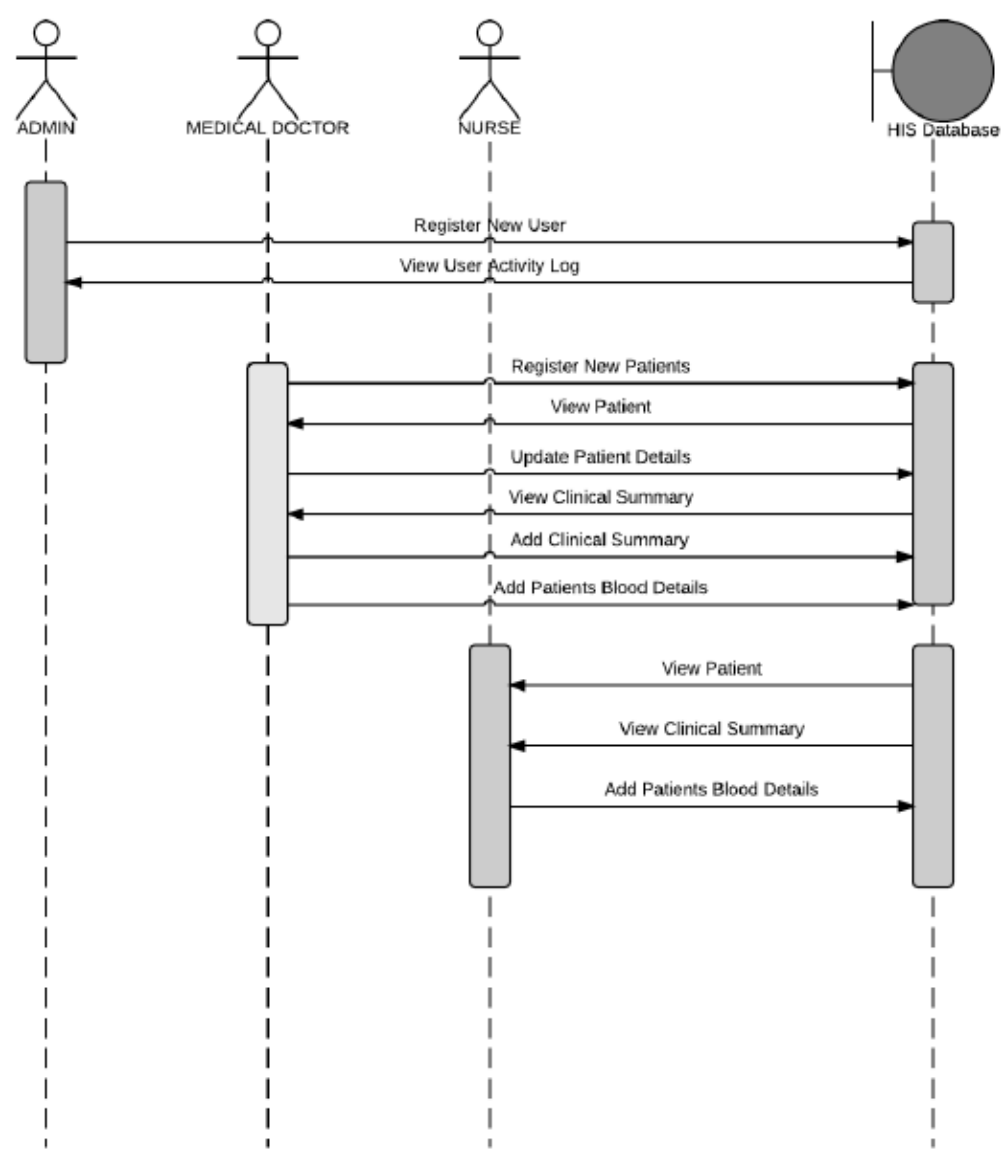

Fig. 12. Sequence diagram of HIS.

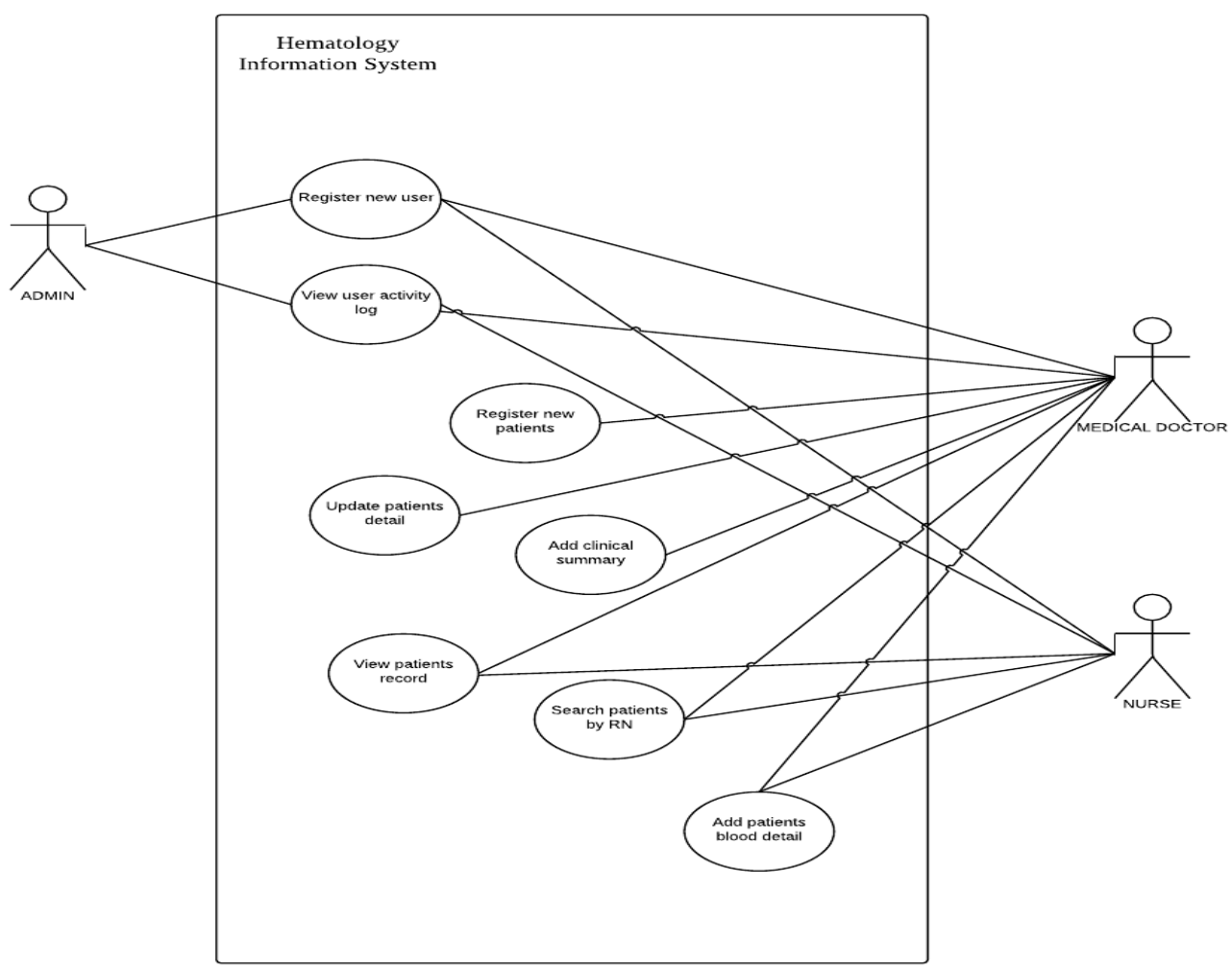

Fig. 13. Use case diagram. 


\section{Coding}

In developing the Hematology Information System, some of tools have been used to design, coding, and deploy the system. The tools shows in Table 3 ease the researcher to develop the system.

Table 3. Software Used in Developing the Hematology Information System

\begin{tabular}{|l|l|}
\hline Tools / Technology & Description \\
\hline Eclipse & $\begin{array}{l}\text { Develop a coding on this software and run the apache server by using this } \\
\text { platform. }\end{array}$ \\
\hline Java Server Pages (JSP) & $\begin{array}{l}\text { JavaServer Pages (JSP) technology provides a simplified, fast way to create } \\
\text { dynamic web content. JSP technology enables rapid development of } \\
\text { web-based applications that are server- and platform-independent. }\end{array}$ \\
\hline MySQL database & $\begin{array}{l}\text { This is a database system that used in the web-based application or } \\
\text { system. That is ideal for both small and large applications. In addition, it is } \\
\text { very fast, reliable and easy to use and compiles on a number of platforms. } \\
\text { The database system runs on a server provided. }\end{array}$ \\
\hline Javascript & $\begin{array}{l}\text { JavaScript is a dynamic scripting language supporting prototype } \\
\text { based object construction. }\end{array}$ \\
\hline Apache & $\begin{array}{l}\text { Apache is generally recognized as the world's most popular Web server } \\
\text { (HTTP server) (Bradley Mitchell, 2013). It provides a full range of Web } \\
\text { server features, such as CGI (Common Gateway Interface), anonymous } \\
\text { user access, virtual domain, server status display, and others. }\end{array}$ \\
\hline LucidChart & $\begin{array}{l}\text { Tools to draw and design UML diagram. To sketch the proposed system } \\
\text { logically. }\end{array}$ \\
\hline iMacros & $\begin{array}{l}\text { Integration testing tools. iMacros can automate it from web } \\
\text { automation/web scripting, to data extraction and to web testing. }\end{array}$ \\
\hline
\end{tabular}

All of the functions use add and update method. There is the first page of the system. During the development process, programming that has been used to implement this system is JSP. Therefore, Eclipse Kepler Web Tools Platform has been used as a development tool. The template of the page was designed by using css bootstrap as mentioned at design phase in previous chapter. The button and the header of the page totally designed by using Adobe software. After making analysis for the system design, and functional flow, the system translated into the system coding to make sure that compiler understand the command. Every single button of each page of the system has an own function.

\subsection{Functional Requirements of HIS}

The Internet application typically runs on a web server. In this report, JSP and java will be the implementation language. To support the requirements, the system will be built on a platform, which supports java. Since Java language is platform independent, the system could be in Windows 98/2000/NT/XP or Unix/Linux platform with a Java server. In this Hematology Information System, hundreds of data will be stored. The data access involves reading and writing. Therefore, it will need a database management system to manage the data.

Based on the above reason, those are the recommended system requirement for Hematology Information System:

1) Computer with processing unit at least $1.5 \mathrm{GHz}$ and above.

2) 512 MB of RAM

3) Portable (No need installation)

4) Operating System:

- Microsoft Windows XP Home Edition (Service Pack 2), Microsoft Windows XP Professional (Service Pack 2), Microsoft Windows XP Professional x64 Edition

- Microsoft Windows Vista, Microsoft Windows 7, Microsoft Windows 8

- Linux/Unix 
For this system, it is a special web site for special users. The server will put inside the hospital's intranet. So, physically, the server should be secure because it is behind the firewall. A steady Internet connection is required for running the web server. DSL high-speed connection or cable connection is recommended, though dial-up connection with at least 56kbps modem can also be considered. Besides, a user friendly GUI (Graphic User Interface) is required for frequent visitors to browse through the web browser. The web browser should be Internet Explorer 7.0 or higher. The user interface will be transparent to the user, and extremely easy to learn. No special skills are required to use the system, just the ability to read and understand the displayed textual information.

\section{Testing}

In this section explain on the testing of HIS to ensure the system is acceptable by the user. It includes the goal of testing, step of testing, result of testing, and the changes made after testing if there is a problem occurred. The testing of the system is important to help in identifying the errors and bugs occur in the system so that the system running smoothly. The integration testing was conducted before the evaluation process start by using iMacros tool. iMacros is a tool that can automate in browser tests. It is also perform in-browser tests of Java, Flash, Flex or Silverlight applets and all AJAX elements. Integration testing tests integration or interfaces between components, interactions to different parts of the Hematology Information System. The form of this testing was shown at Appendix $C$.

Next stage of testing is the user acceptance testing (UAT). The form of the UAT as shown at Appendix D The evaluation process was conducted at HUSM and Faculty of Medicine and Science Health, USIM. We want to ensure that our software can be applied to any hematology department. The evaluation processes consist of system acceptance testing by user. To test the major component and module of the Hematology Information System, three medical doctors and two student of medicine have been decided to test the system in real environment. The two students were act as nurses. They used the system at the same time in the same network. The purpose is to find out whether there is any error or fault in the program. As for integration testing, all the system components work had together as required by the system requirement. With regard to system testing, the entire system was tested with all possible triggers and the system was capable and succeeded to handle the said triggers. All of the testing conducted allowed the researcher to detect errors and to ensure the quality; security and reliability of the program code from the earliest stages of the development until the final stage and managed to reduce potential errors. Below is the example of the testing requirement

\section{Admin Login and Register User}

Goals:

This testing is carried out to verify that all the features fully functional. This login part is very important to make sure that the system is running properly based on the priority of each user.

Steps:

- Admin login the system and register the medical doctor and nurse.

- Medical doctor and nurse login the system.

- Results:

- Activity log of medical doctor and nurse were recorded in database and admin can view their activity $\log$.

- Medical doctor and nurse view a different page after login the Hematology Information System.

\section{Patients Registration}

Goals:

To make sure that registration form and the information entered by medical doctor pass through the 
validation process.

Steps:

- Click the "Register" button on the sidebar menu.

- Medical doctor should enter the patient's information and click "Submit" button at the bottom of the page.

- Results:

- Once medical doctor submit the registration form, the system directly go to the patient's detail page.

- If the submission is failed to pass through the validation process, the system will return back to the registration page again and medical doctor must correct the erroneous.

\section{Search Patients By Registration Number}

Goals:

Medical doctor and nurse carry out this testing to verify that search function will work after clicking the search button.

Steps:

- Entered patient's RN into the search box, then click the search button

- Results:

- Within 2 seconds, the patient's detail appears at the bottom of the search box.

- If the user entered the wrong patients RN, the system will noticed to enter a RN again.

\section{Edit Patient Details}

Goals:

Medical doctor carry out this testing to verify that update function is running properly with real running time Hematology Information System. This function is prioritized to medical doctor only.

Steps:

- Edit patient's category, from Outpatient to Inpatient.

- Update the changes by clicked the update button.

- Results:

- The system shows the related patient, changes into the new category.

\section{Result and Analysis}

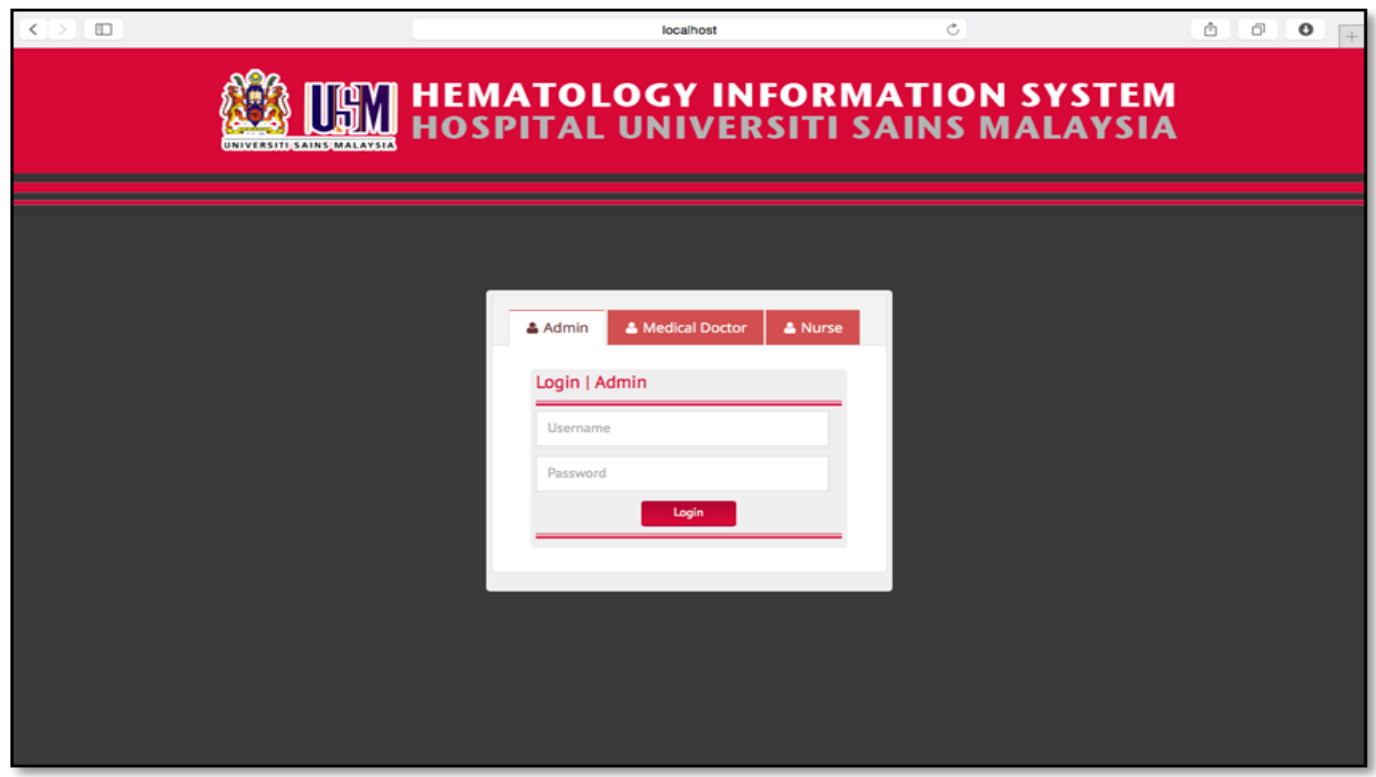

Fig. 14. Login page. 
During implementation, we faced problems when conversion data from old system to new system. The old database is had been un-normalized and same. The table is not used, we need to export the data into excel for matching our new database. From the solution, we successful convert our database. During the user acceptance testing (UAT), they have commented on the design phase that required the calculation on blood series. The reason is to automate the blood calculation and reduce the human errors on the calculation. Finally, we have enhanced the user requirement.

Login Page and Activity Log Page

Once the medical doctor and nurse login into the HIS, their username and timestamp of login will be recorded into the activity_log table. This page will be automated refresh within 60 seconds. So that, admin can view and trace who use the HIS at that time.

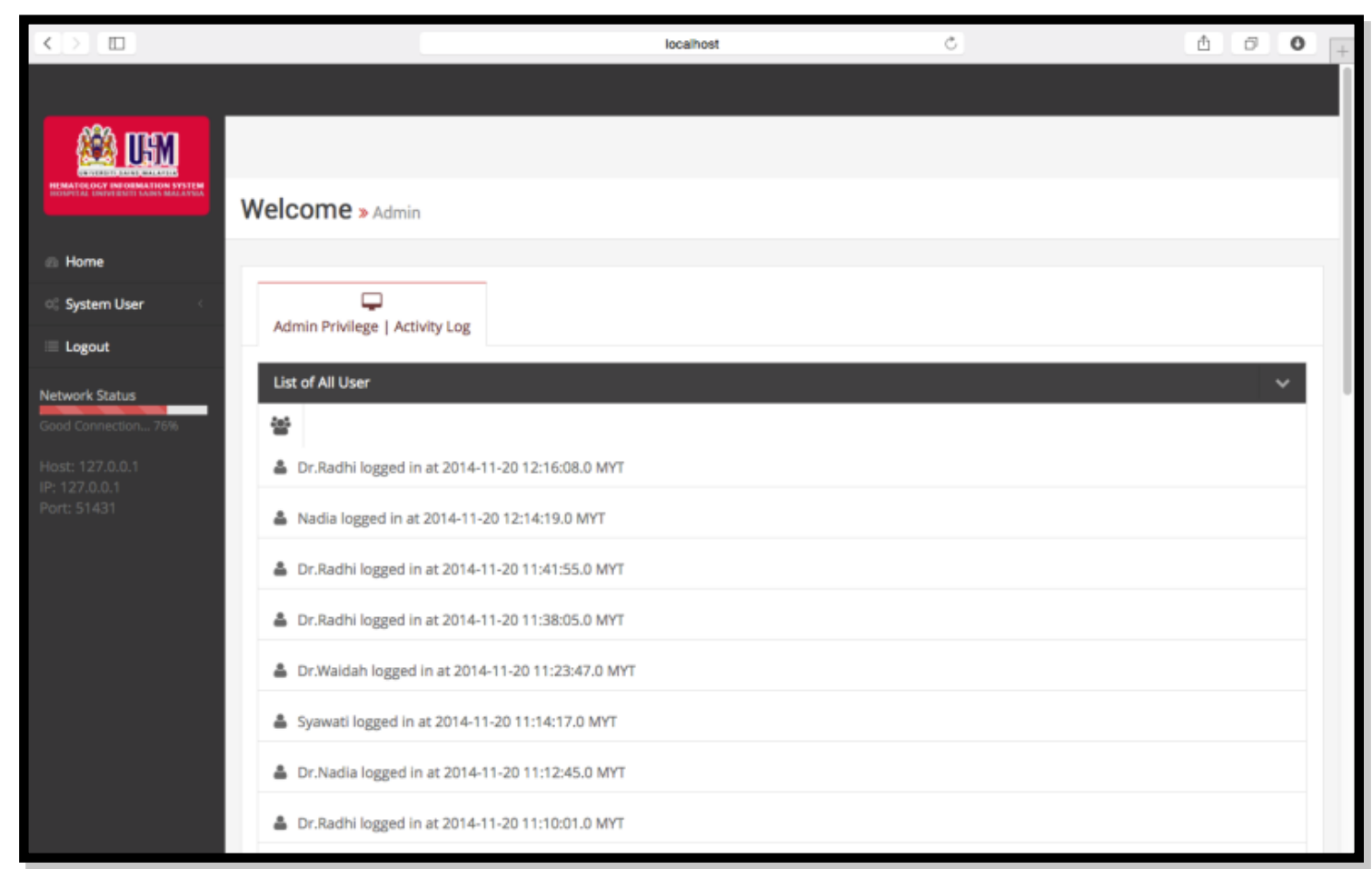

Fig. 15. Activity log.

$$
S(\text { user_id, pass, role })=\left\{\begin{array}{ccc}
1, & \text { if } & \text { open table Admin } \\
2, & \text { if } & \text { open table Doctor } \\
\text { Otherwise, } & \text { if } & \text { open table Nurse }
\end{array}\right.
$$

Input: user_id, pass, role

Read user_id;

Read pass;

Read role;

Perform Eq (1)

Search user_id

Search pass

End 


\section{Conclusion}

In conclusion, by performing Agile methodology can reduced time consuming and meet the user requirements. Although in the beginning will takes more time to finalise the user requirement and design but during the development it takes less time. At the same time, the full commitment from the user in user interface design and create the database design. The medical data can consider as high-risk application and need to develop more on the security features.

\section{Appendixes}

\section{Appendix A}

\section{User Requirement Questionnaire}

\section{Hematology Information System}

Types of Requirements:

Requirements state expectations at two levels. The first are high-level functional requirements that state goals the system will achieve. The second are more fine-grained procedural expectations that describe how the system will behave. As might be expected, it is possible to fulfill a set of functional requirements in multiple ways using different instantiations of procedural requirements.

1) What are the perspectives and objectives of the project? Based on the problem.

2) What are the functions and workflow that the system must be able to perform?

3) What are the types of information that a system must be able to process?

4) What the new features do you want in this system?

5) What type of security do you want in this system? Except login session.

6) What the screen do after user login the system?

7) Who can use or access the system? Based on user classes and characteristics.

8) What are the types of operating environments that can run this system?

9) What are the types of hardware interface use in this system? E.g.: Internet connection.

10) What are the types of software interface use in the system? E.g.: Web Browser.

11) What is the communication interface uses in this system? E.g.: IP, HTTP and MYSQL.

\section{Appendix B}

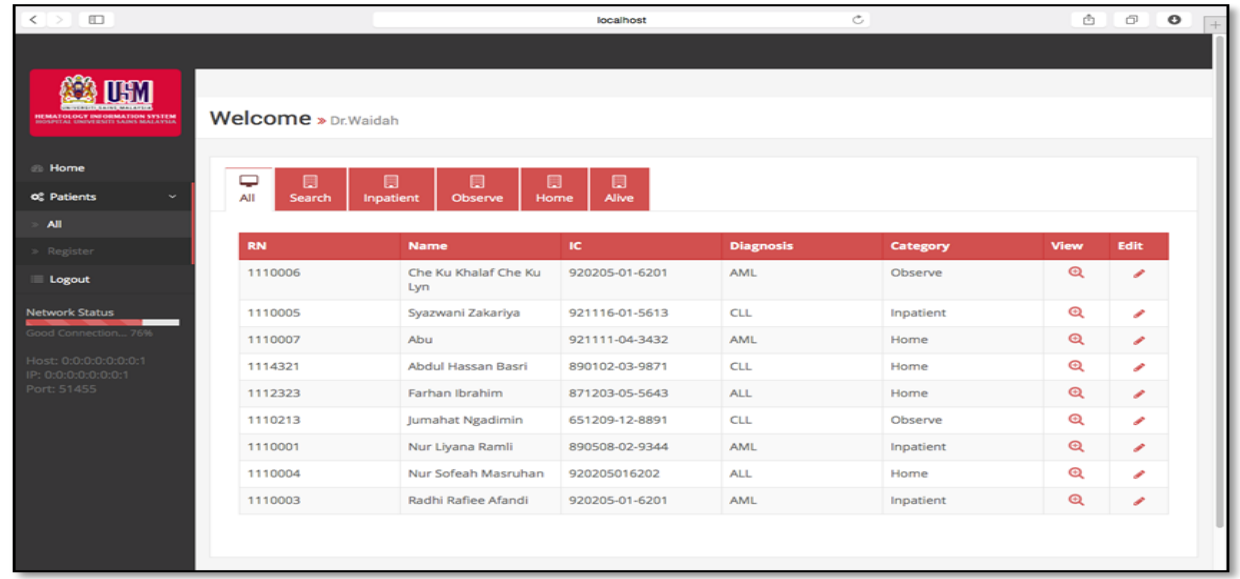

List of all patients page 


\begin{tabular}{|c|l|}
\hline Part & \multicolumn{1}{c|}{ Description } \\
\hline Patients > All (sidebar) & Show all the registered patients in te system. \\
\hline View button & $\begin{array}{l}\text { Once the user click on the view button, the system will show the detail of that patient, } \\
\text { such as biodata, clinical summary and blood series }\end{array}$ \\
\hline Edit button & Edit and update patient details. Only medical doctor can perform this action \\
\hline
\end{tabular}

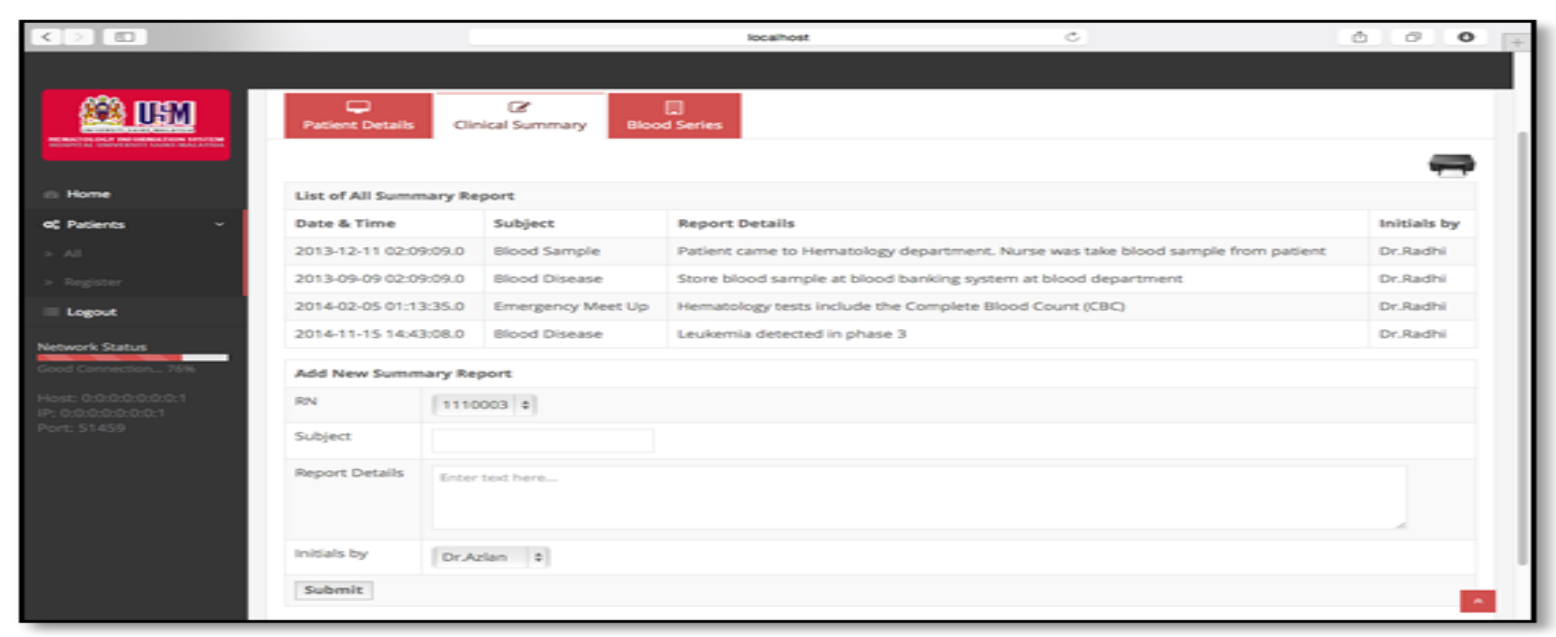

Patient's clinical summary record

\begin{tabular}{|c|l|}
\hline Part & \multicolumn{1}{|c|}{ Description } \\
\hline Add new summary report & $\begin{array}{l}\text { When click 'submit' button, the input entered by user will automatically update by the } \\
\text { system and the time is record via timestamp. This action only can be done by medical } \\
\text { doctor. Medical doctor have a privilege to add new clinical summary record }\end{array}$ \\
\hline
\end{tabular}

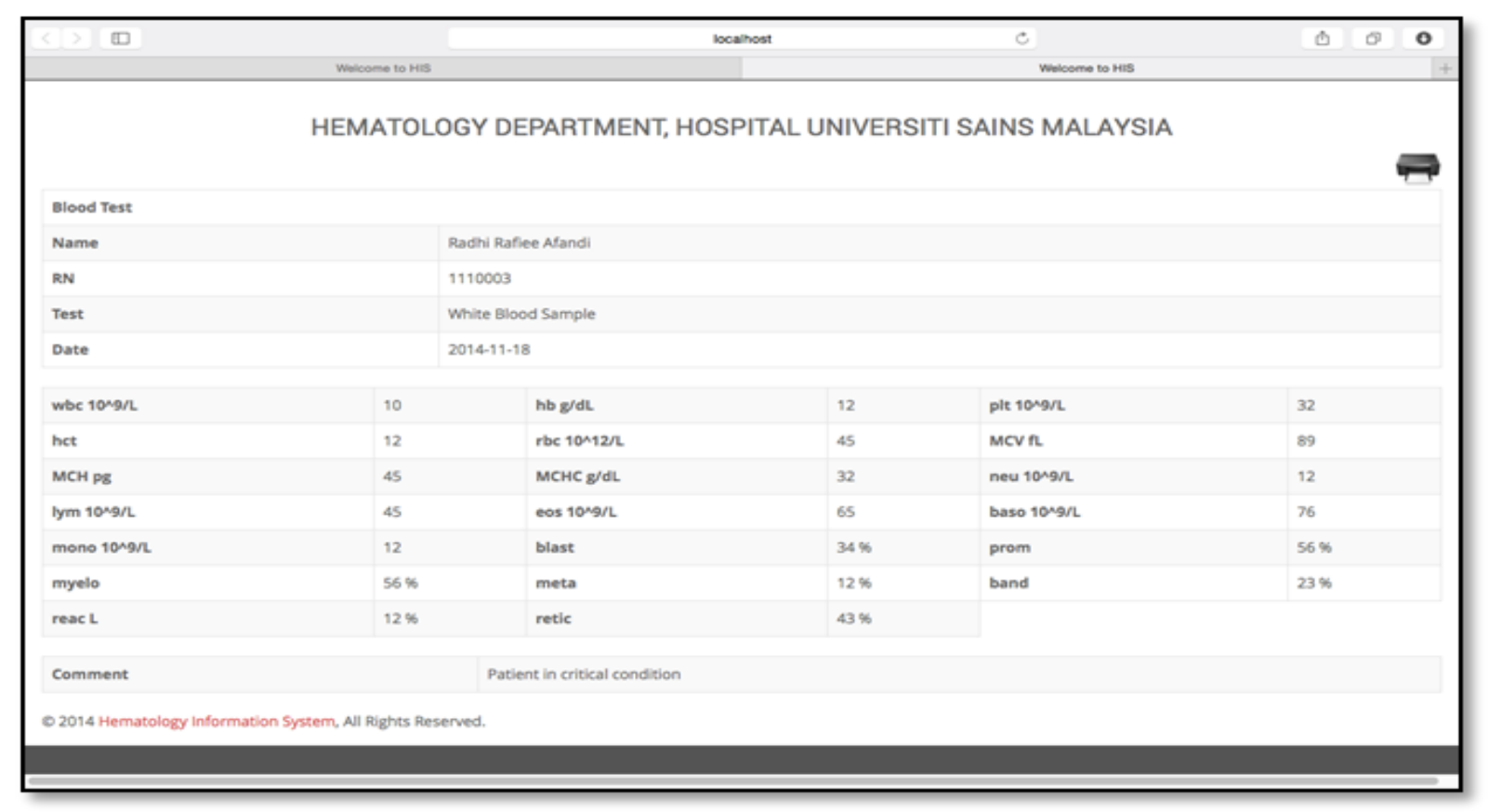

\section{Blood Series printout version}

\begin{tabular}{|c|l|}
\hline Part & \multicolumn{1}{c|}{ Description } \\
\hline Blood series tab & $\begin{array}{l}\text { From blood series tab, user can print the blood series for each paients. This action are } \\
\text { performed by medical doctor or nurse. }\end{array}$ \\
\hline
\end{tabular}

Appendix C

\section{Result of Integration Testing}




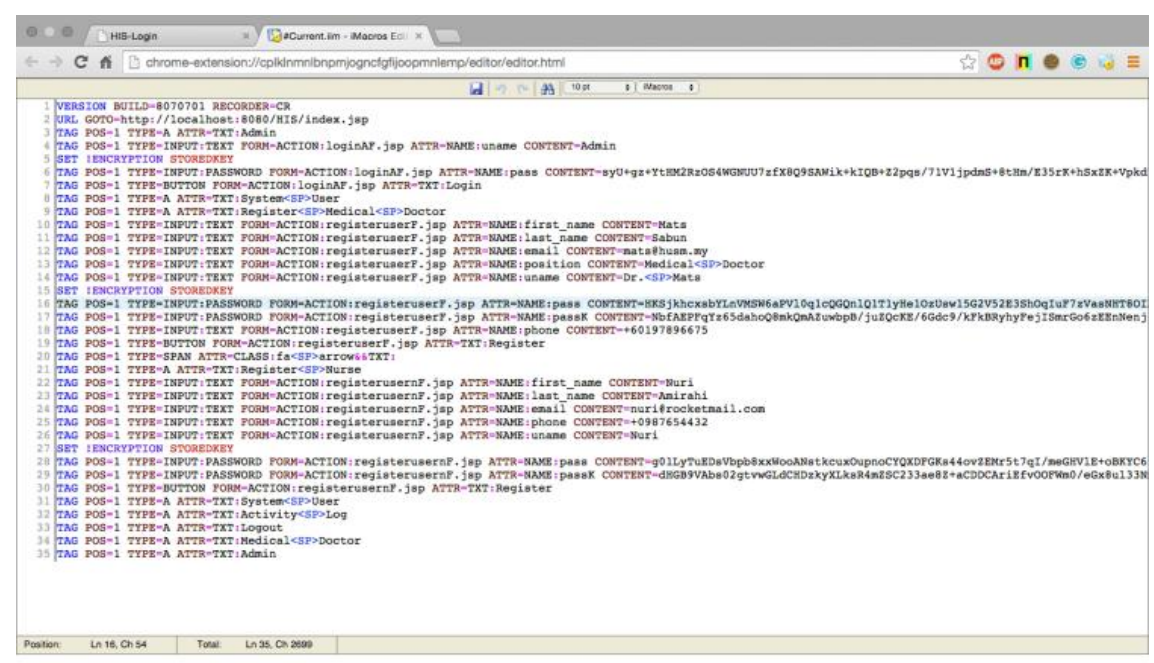

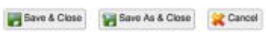

Admin module.

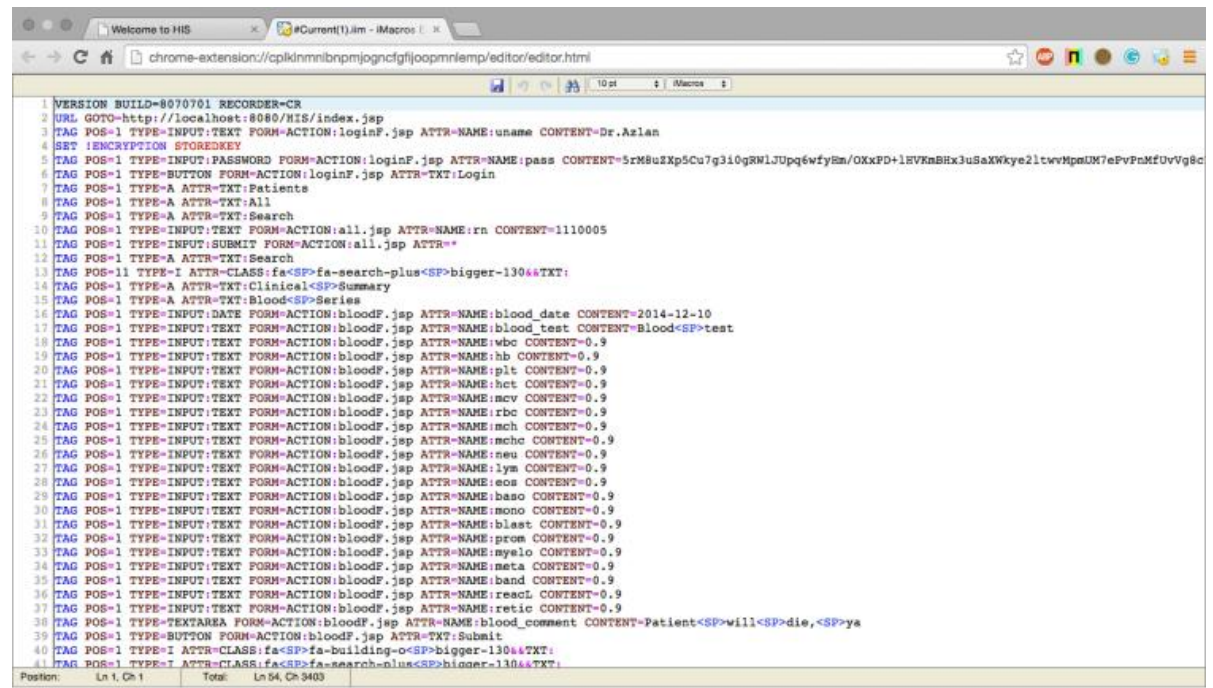

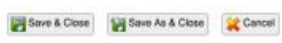

Medical doctor module.

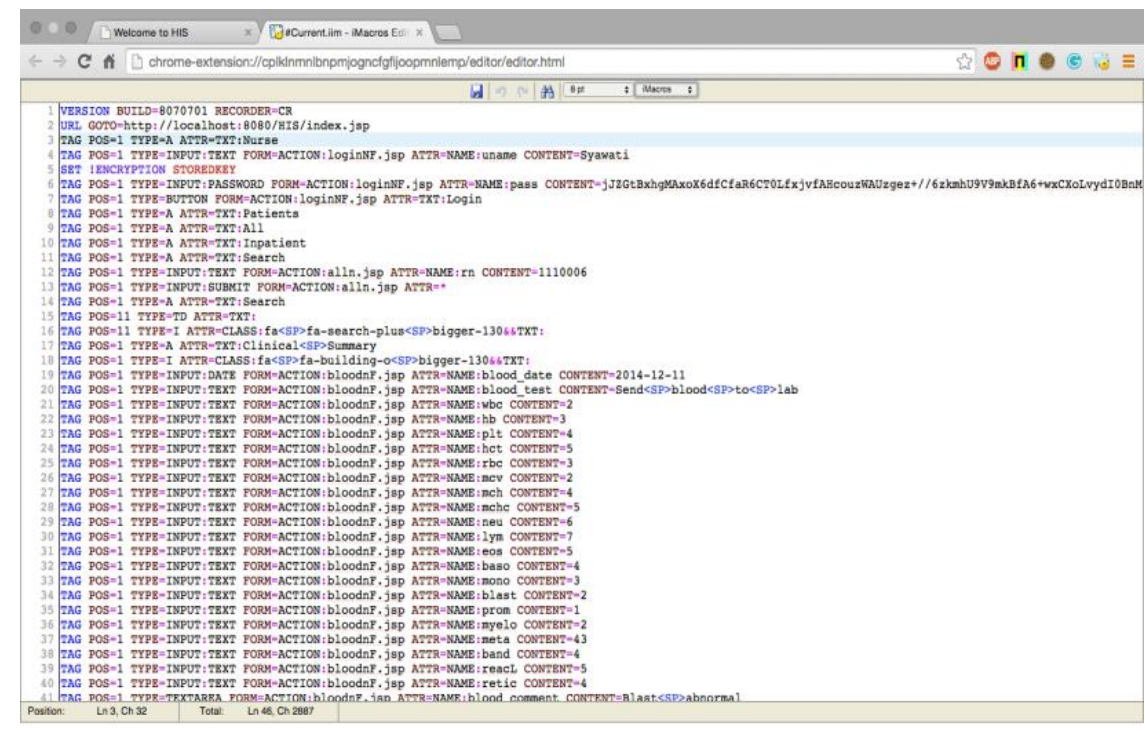

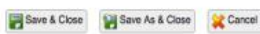

Nurse module. 


\section{Appendix D}

\section{Hematology Information System Evaluation Form}

\begin{tabular}{|c|c|c|c|}
\hline No. & Criteria & Yes & No \\
\hline 1. & Is the level of language that the system offers clearly indicated? & & \\
\hline 2. & Is it easy to start the system? & & \\
\hline 3. & $\begin{array}{c}\text { Is the user interface easy to understand? (For example, is the screen layout clear and } \\
\text { easy to interpret?) }\end{array}$ & & \\
\hline 4. & Is it easy to navigate through the program? & & \\
\hline 5. & $\begin{array}{c}\text { Are icons that are used to assist navigation (e.g. back to the homepage, exit) clear and } \\
\text { intelligible? }\end{array}$ & & \\
\hline 6. & Is it always clear to the learner which point s/he has reached in the program? & & \\
\hline 7. & Is the learner offered useful feedback if s/he gets something wrong? & & \\
\hline 8. & If the system use automated data retrieval, is it effective? & & \\
\hline 9. & Do you think the system is secure? & & \\
\hline 10. & Is the system relevant to your department? & & \\
\hline
\end{tabular}

\section{Acknowledgment}

The research for this paper was financially supported by the Universiti Sains Islam Malaysia, grant no. PPP/UTG- 0213/FST/30/12213.

\section{References}

[1] Waidah, I., Rosline, H., \& Swift, S, (2010). Detecting leukaemia (AML) blood cells using cellular automata and heuristic search. Intelligent Data Analysis (IDA 2010) University of Arizona, 54 - 64

[2] Wan, F. W. A., Aliza, S., \& Nur, Z. I. Z. (2008). Universiti teknologi petronas health, safety and environment system. Proceedings of the International Symposium On Information Technology 2008 (ITSim08).

[3] Norhaziah, A., Nor, N., \& Nasratun, M. (2008). Pet shop management system for klinik veterinar and surgeri jawhari. Audio, Transactions of the IRE Professional Group.

[4] Rajendran, S., Arof, H., Mokhtar, N., Nubin, M., \& Yegappan, S. I. (2011). Dual modality search and retrieval technique analysis for leukemic information system. Scientific Research and Essays, 247-255

[5] Jeff, Z., \& Dennis, D. (2007). Software development and related security issues. Proceedings of IEEE Southeastcon. 2007.

[6] Meier, J. D. (2006). Web application security engineering. Security and Privacy, 4(4),16-24.

[7] Mark, C., \& Rudolph, A. (2006). Web application security assessment tools. Security and Privacy, 4(4), $32-41$.

[8] Myat, M. M., \& Khin, H. S. H. (2005). Security on software life cycle using intrusion detection system. Proceedings of the 6th Asia Pacific Symposium on Information and Telecommunication Technologies APSITT 2005 Proceedings.

[9] Rigney, C., Willens, S., Rubens, A., \& Simpson, W. (2000). Remote authentication dial in user service (radius).

[10] Hassan, R. (2014). Vulnerability distribution scoring for software product security assessment. International Journal of Information and Computer Security (pp. 270 - 285).

[11] Lawrence, T., \& Gail, J. A. (2013). Extensible policy framework for heterogeneous network 
environments. International Journal of Information and Computer Security, 5(4), 251-274.

[12] Fabrizio, M., Federico, C., Frank, Lloyd, D., Manuela, F., Fausto, J. P., Antonietta, M., Domenico, P., Gianmario, S., Francois, M., \& Raffaele, D. C. (2014). Implementation strategies of systems medicine in clinical research and home care for cardiovascular disease patients. European Journal of Internal Medicine, 785-794.

[13] Mar, M., Jose, A. M., Begona, M. S., Diego, B., \& Montserrat, R., (2013). Interoperability of clinical decision-support systems and electronic health records using archetypes: A case study in clinical trial eligibility. Journal of Biomedical Informatics, 676-689.

[14] Andrew, R. P., Tahsin, K., Sharath, C., Jing, J. G., Xia, L., William, Bornstein, D. C., David, L., Sam, H., Joel, \& H. S. (2013). The Analytic information warehouse (AIW): A platform for analytics using electronic health record data. J Biomed Inform, 46(3), 410-424.

[15] Gabriela, J., Theodore, D. H., \& Frank, M. (2014). Integrating agile and user-centered design. Agile Conference (Agile).

[16] Uchiyama, S., Kubo, A., Washizaki, H., \& Fukazawa, Y. (2014). Detecting design patterns in objectOriented program source code by using metrics and machine learning. Journal of Software Engineering and Applications. Retrieved, 2014, from http://dx.doi.org/10.4236/jsea.2014.712086.

[17] Kevin, B., Kirk, L., Thaine, R., Matt, M., Christopher, S., Al, R., Daniel, V., \& March, R. (2014). Security and audit trail capabilities of a facilitated interface used to populate a database with text and graphical data using widely. Journal of Software Engineering and Applications, 713-719.

[18] Walid, M., Rebecca, T., Tobias, R., \& Rainer, K. (2014). On the comprehension of program comprehension. ACM Trans. Softw. Eng. Methodol, 23(4). Retrieved, 2014, from http://dx.doi.org/10.1145/2622669.

[19] Dan, H., Ling, M. Z., Lu, Z., Gregg, R., \& Hong, M. (2014). A unified test case prioritization approach. ACM Trans. Softw. Eng. Methodol, 24(2), Retrieved, 2014, from http://dx.doi.org/10.1145/2685614

[20] Rana, A., Singh, S. P., Soni, R., \& Jolly, A. (2014). Categorization of software release risks and its abatement strategy. Journal of Software Engineering and Applications, Retrieved, 2014, from http://dx.doi.org/10.4236/jsea.2014.712091

[21] Bernardo, E. R., Prikladnicki, M. M., Gabriel, N., \& Alejandro, O. (2014). Software kaizen: using agile to form high performance.

[22] Gabriela, J., Theodore, D. H., \& Frank, M. (2014). Integrating agile and user-centered design.

[23] Maria, P., \& Casper, L. (2014). Deepening our understanding of communities of practice in large-scale agile development.

[24] Weinberg, R. (1998). One renegade cell, the quest for the origins of cancer. London Weidenfeld and Nicolson.

[25] Hassan, R. (1996). Diagnosis and outcome of patients with Acute Leukemia. Heamotology Department. Malaysia, Universiti Sains Malaysia. Degree of master of Medicine.

[26] Waidah, I. (2012). Automated detection and classification of leukaemia cells. Information System and Computing Department, Brunel University, U.K. Phd Thesis.

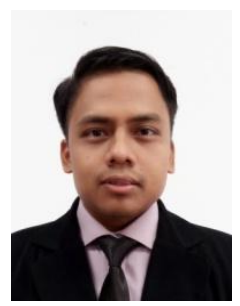

Radhi Rafiee Afandi is a final year student bachelor of computer science majoring in information security of assurance in Islamic Science University of Malaysia (USIM), one of the Malaysia's public institutes. In USIM, He received to the true latitude of computer science. The core courses gave him a detailed knowledge in each field. The lab courses and projects also gave him the programming skills. He was participated many programming competition in national and international level. Radhi Rafiee Afandi is vice the president of 
Young Muslim Leader of The Future in the campus. Through this organization, he's been doing a lot of various leadership and community engagement programs held locally and abroad.

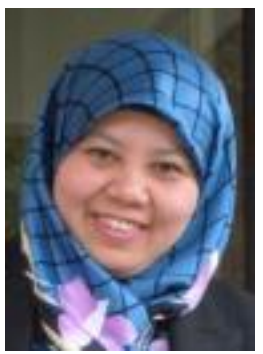

Waidah Ismail has completed her diploma in computer science in Institute of Technology Mara, Malaysia and now known as University Technology Mara. After her graduation, She continued in Bsc(Hons) in University Liverpool, UK. After graduated, She is working in the Banking as a security analyst officer for almost 10 years. She continue her master in information technology in University Technology Mara, Malaysia as a part-time and completed her master within one and a half years. Then she change her work environment into education. And now, She is a lecturer in Universiti Sains Islam Malaysia for almost 8 years. She was graduated her $\mathrm{PhD}$ in information system and computing from Brunel University, UK. She is also member of IEEE and ACM. She has published a few papers on medical domain during my PhD in 2012. She has published a book on Security Network and Standard. She also hold a twelve grant as primary and co-researcher. She has published nearly 25 conferences and journal paper in since I'm working with USIM. Now, my research interest will be on medical domain

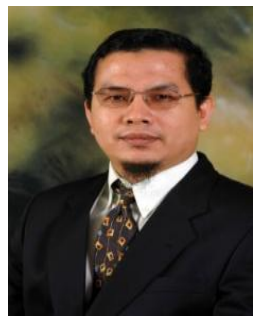

Azlan Husin is a senior medical lecturer, consultant physician and clinical hematologist in Department of Internal Medicine, Universiti Sains Malaysia, Kelantan. Currently he is the co-ordinator for Haematologic Stem Cell Transplant Unit, Hospital Universiti Sains Malaysia. He was awarded medical degree by UKM in 1996 and He received his master in medicine (internal medicine) from Universiti Sains Malaysia, in 2005. His research interests include leukemia, lymphoma, myeloma, supportive care in cancer patients and also benign hematological disease. He has published many papers and acquiring grants related to his area. Dr Azlan is active member of Malaysian Society of Hematology and Malaysian Society of Transplantation.

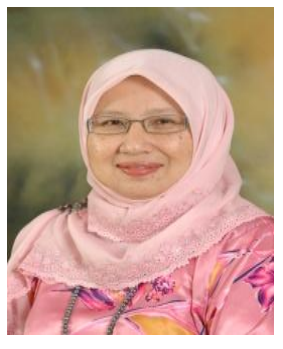

Rosline Hassan is a medical lecturer and consultant hematopathologist in Hematology Department, Universiti Sains Malaysia, Kelantan. Currently she is the deputy dean of research. She was awarded medical degree from UKM in 1991 and She received her master in medicine (pathology)(hematol) in 1997. Her research interests include leukemia, thalassemia and molecular genetics of hematological disorders. She has published many papers and acquiring many grants related to her area. Dr Rosline is active and is elected as committee member of a member Malaysian Society of Hematology. She is awarded as fellow for college of Pathologist, Malaysia 